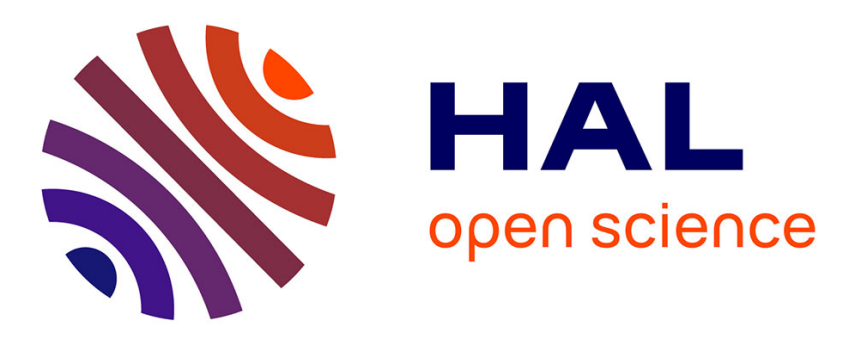

\title{
RAD54 is essential for RAD51-mediated repair of meiotic DSB in Arabidopsis
}

Miguel Hernandez Sanchez-Rebato, Alida Bouatta, Maria Gallego, Charles I. White, Olivier da Ines

\section{- To cite this version:}

Miguel Hernandez Sanchez-Rebato, Alida Bouatta, Maria Gallego, Charles I. White, Olivier da Ines. RAD54 is essential for RAD51-mediated repair of meiotic DSB in Arabidopsis. PLoS Genetics, 2021, 17 (5), pp.e1008919. 10.1371/journal.pgen.1008919 . hal-03374679

\section{HAL Id: hal-03374679 \\ https://hal.science/hal-03374679}

Submitted on 12 Oct 2021

HAL is a multi-disciplinary open access archive for the deposit and dissemination of scientific research documents, whether they are published or not. The documents may come from teaching and research institutions in France or abroad, or from public or private research centers.
L'archive ouverte pluridisciplinaire HAL, est destinée au dépôt et à la diffusion de documents scientifiques de niveau recherche, publiés ou non, émanant des établissements d'enseignement et de recherche français ou étrangers, des laboratoires publics ou privés. 


\title{
RAD54 is essential for RAD51-mediated repair of meiotic DSB in Arabidopsis
}

\author{
Miguel Hernandez Sanchez-Rebato $₫$, Alida M. Bouatta $\mathbb{D}^{\mathbb{D}}$, Maria E. Gallego $₫$, Charles \\ I. White $\mathbb{D}{ }^{*}$, Olivier Da Ines $\mathbb{D}$ * \\ Institut Génétique Reproduction et Développement (iGReD), Université Clermont Auvergne, UMR 6293 \\ CNRS, U1103 INSERM, Clermont-Ferrand, France \\ *charles.white@uca.fr (CIW); Olivier.da_ines@uca.fr (ODI)
}

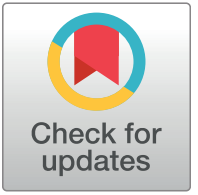

\section{OPEnACCESS}

Citation: Hernandez Sanchez-Rebato M, Bouatta AM, Gallego ME, White Cl, Da Ines 0 (2021) RAD54 is essential for RAD51-mediated repair of meiotic DSB in Arabidopsis. PLoS Genet 17(5): e1008919. https://doi.org/10.1371/journal. pgen.1008919

Editor: Mathilde Grelon, INRA, FRANCE

Received: June 4, 2020

Accepted: May 3, 2021

Published: May 18, 2021

Copyright: ๑ 2021 Hernandez Sanchez-Rebato et al. This is an open access article distributed under the terms of the Creative Commons Attribution License, which permits unrestricted use, distribution, and reproduction in any medium, provided the original author and source are credited.

Data Availability Statement: All relevant data are within the manuscript and its Supporting Information files.

Funding: This work was supported by the CNRS, INSERM, Université Clermont Auvergne, a grant from the French government through the IDEXISITE-CAP20-25 initiative (16-IDEX-0001-CAP2025 to 0. D.I) and the European Union (H2020MSCA-ITN-2017:765212-MEICOM to C.I.W). The doctoral fellowship of $\mathrm{MH}$ is financed by the European H2020-MSCA-ITN-2017:765212-

\section{Abstract}

An essential component of the homologous recombination machinery in eukaryotes, the RAD54 protein is a member of the SWI2/SNF2 family of helicases with dsDNA-dependent ATPase, DNA translocase, DNA supercoiling and chromatin remodelling activities. It is a motor protein that translocates along dsDNA and performs multiple functions in homologous recombination. In particular, RAD54 is an essential cofactor for regulating RAD51 activity. It stabilizes the RAD51 nucleofilament, remodels nucleosomes, and stimulates the homology search and strand invasion activities of RAD51. Accordingly, deletion of RAD54 has dramatic consequences on DNA damage repair in mitotic cells. In contrast, its role in meiotic recombination is less clear. RAD54 is essential for meiotic recombination in Drosophila and C. elegans, but plays minor roles in yeast and mammals. We present here characterization of the roles of RAD54 in meiotic recombination in the model plant Arabidopsis thaliana.

Absence of RAD54 has no detectable effect on meiotic recombination in otherwise wild-type plants but RAD54 becomes essential for meiotic DSB repair in absence of DMC1. In Arabidopsis, dmc1 mutants have an achiasmate meiosis, in which RAD51 repairs meiotic DSBs. Lack of RAD54 leads to meiotic chromosomal fragmentation in absence of DMC1. The action of RAD54 in meiotic RAD51 activity is thus mainly downstream of the role of RAD51 in supporting the activity of DMC1. Equivalent analyses show no effect on meiosis of combining $d m c 1$ with the mutants of the RAD51-mediators RAD51B, RAD51D and XRCC2. RAD54 is thus required for repair of meiotic DSBs by RAD51 and the absence of meiotic phenotype in rad54 plants is a consequence of RAD51 playing a RAD54-independent supporting role to $\mathrm{DMC} 1$ in meiotic recombination.

\section{Author summary}

Homologous recombination is a universal pathway which repairs broken DNA molecules through the use of homologous DNA templates. It is both essential for maintenance of genome stability and for the generation of genetic diversity through sexual reproduction. A central step of the homologous recombination process is the search for and invasion of a homologous, intact DNA sequence that will be used as template. This key step is 
MEICOM contract. The funders had no role in study design, data collection and analysis, decision to publish, or preparation of the manuscript.

Competing interests: The authors have declared that no competing interests exist. catalysed by the RAD51 recombinase in somatic cells and RAD51 and DMC1 in meiotic cells, assisted by a number of associated factors. Among these, the chromatin-remodelling protein RAD54 is a required cofactor for RAD51 in mitotic cells. Understanding of its role during meiotic recombination however remains elusive. We show here that RAD54 is required for repair of meiotic double strand breaks by RAD51 in the plant Arabidopsis thaliana, and this function is downstream of the meiotic role of RAD51 in supporting the activity of DMC1. These results provide new insights into the regulation of the central step of homologous recombination in plants and very probably also other multicellular eukaryotes.

\section{Introduction}

Homologous recombination (HR) is an universally conserved DNA repair mechanism essential for maintaining genomic integrity and ensuring genetic diversity $[1,2]$. In somatic cells, HR is used to repair DNA breaks caused by environmental and endogenous factors and is critical in the recovery of stalled and collapsed replication forks. In meiotic cells of the majority of studied eukaryotes, HR is essential for accurate chromosome segregation during the first meiotic division, also generating genetic diversity among meiotic products [3,4].

Homologous recombination is a DNA repair pathway that involves the use of a homologous template for restoration of the original sequence. It is initiated by DNA double-strand breaks (DSBs) and subsequent resection of the 5 '-ended strands of the DSB, generating long 3' single-stranded DNA (ssDNA) overhangs [5]. The ssDNA overhangs are further coated by replication protein $\mathrm{A}$ (RPA), protecting them from nucleases and removing secondary structures [6,7]. In a subsequent step, RPA is displaced by the recombinase RAD51 in somatic cells, or RAD51 and DMC1 in meiotic cells, forming a right-handed helical nucleofilament on the exposed single-stranded DNA (ssDNA) flanking the DSB [8,9]. This helical nucleofilament performs the homology search and catalyses the invasion of a homologous DNA template sequence by the $3^{\prime}$-ended DNA strands, which are then extended through DNA synthesis. The resulting joint recombination intermediate can be processed through several different pathways eventually leading to separation of the recombining DNA molecules and restoration of chromosome integrity [1,2].

The nucleoprotein filament is the active protein machinery for DNA homology search and strand exchange during HR. In somatic cells, the nucleoprotein filament is formed by the RAD51 recombinase. The in vivo assembly and disassembly of the RAD51 nucleoprotein filament is a highly dynamic process, regulated via the coordinated actions of various positive and negative factors, and notably, the RAD51 mediators $[10,11]$. These proteins, involved in the regulation of the formation, stability and activity of the RAD51 nucleofilament, include the RAD51 paralogues and the SHU complex that are known to be essential RAD51 positive regulators (for reviews see [10-13]. The RAD51 paralogues are important for homologous recombination and DNA repair in somatic cells $[11,14]$. In contrast, clear understanding of their roles during meiosis remains elusive. Budding yeast has two RAD51 paralogues, Rad55 and Rad57, which form a heterodimer, and are essential for meiotic recombination [15-17] and 4 Shu proteins (Psy3, Csm2, Shu1 and Shu3) forming the Shu/PCSS complex that is also required for Rad51 filament assembly and meiotic recombination [18]. Vertebrates, like Arabidopsis thaliana, have five RAD51 paralogues (in addition to DMC1): RAD51B, RAD51C, RAD51D, XRCC2 and XRCC3 which form different complexes [10-13]. Vertebrate mutants for any of the RAD51 paralogues are embryonic lethal and this has hampered the study of 
their meiotic phenotypes. Nevertheless, a number of studies have demonstrated that RAD51C and XRCC 3 are essential for meiotic recombination both in vertebrates and plants [19-29]. In contrast, the possible meiotic roles of RAD51B, RAD51D and XRCC2 are less clearly understood. These three genes are highly expressed in meiotic tissues in animals [30-32] and plants [33-35]. In humans, mutation in XRCC2 has been linked to meiotic arrest, azoospermia and infertility [36] and absence of RAD51B or RAD51D lead to meiotic defects in the moss Physcomitrella patens and rice, respectively [37-39]. The Arabidopsis $x r c c 2$ mutant and, to a lesser extent $\mathrm{rad} 51 \mathrm{~b}$, have been associated with increased meiotic recombination rates, but all three mutants are fully fertile and present no detectable meiotic defects [26,40-42]. Vertebrate genomes also encode two Shu-related proteins, SWS1-SWSAP1, which form a complex dispensable for mouse viability but essential for meiotic progression [43]. To date, Shu proteins have not been identified in plants.

RAD51 nucleofilament activity is further supported by the highly conserved RAD54 protein, which belongs to the SWI2/SNF2 DNA helicase family. It is a dsDNA-dependent ATPase that uses energy from ATP hydrolysis to translocate along dsDNA. It is thus a motor protein and performs multiple functions in homologous recombination. In particular, RAD54 is an essential cofactor stimulating RAD51 activity. It has been shown to stabilize the RAD51 nucleofilament, remodel nucleosomes, stimulate homology search and strand invasion activity of RAD51, dissociate bound RAD51 after completion of strand exchange and even to catalyse branch migration [44-46]. Accordingly, deletion of RAD54 has dramatic consequences on DNA damage repair in mitotic cells (For reviews see [44-46]).

The role of RAD54 in meiotic recombination is less clear. In Drosophila and C. elegans, which exclusively rely on RAD51 (not DMC1), RAD54 is essential for meiotic recombination [47-49]. Yet, in most eukaryotes, meiotic HR is mediated by RAD51 and the meiosis-specific DMC1 $[8,50]$. Interestingly however, while RAD51 is essential for homology search and strand invasion in mitotic cells, it only plays an accessory role for DMC1 in meiosis [51,52]. Thus, $\mathrm{DMC1}$ is the active meiotic recombinase but requires the support of RAD51 to function $[51,52]$. Accordingly, data from budding yeast have demonstrated that Rad51 activity is downregulated during meiosis to favour Dmcl catalysing DNA strand-exchange using the homologous chromosome as a template [51,53-56].

In yeast, down-regulation of Rad51 activity is mediated by the coordinated phosphorylation of Hed1 and the Rad51-cofactor Rad54 by the meiosis-specific kinase Mek1 [53-59]. Hed1 is a meiosis-specific protein that binds to Rad51, impeding access of Rad54 and thereby restricting activity of Rad51 nucleofilaments in meiosis $[54,57,58,60]$. Phosphorylation of Rad54 by Mek1 also reduces its affinity for Rad51 $[53,61]$. Thus, both pathways downregulate Rad51 through inhibition of Rad51-Rad54 complex formation and this in turns favour Dmc1-dependent inter-homologue recombination. In accordance with this down-regulation, Rad54 is also not essential for Dmcl activity and plays a relatively minor role in meiotic recombination in budding yeast [62-68]. This is however due to the presence of a second, Dmc1-specific Rad54 homologue, Rdh54/Tid1 [64,66-68]. Biochemical and genetic experiments have demonstrated that Rdh54 preferentially acts with Dmc1 to promote inter-homologue recombination whereas Rad54 preferentially stimulates Rad51-mediated strand invasion for sister chromatid repair of excess DSBs $[62,63,66,69,70]$.

In mouse, two RAD54 homologues, RAD54 and RAD54B, have been identified. Both are required for somatic recombination but neither is essential for meiotic recombination as single and double mutant mice are fertile, although RAD54 may be needed for normal distribution of RAD51 on meiotic chromosomes [71,72]. To date in plants, only one RAD54 orthologue has been characterized (Arabidopsis locus AT3G19210). As in yeast and mammals, Arabidopsis RAD54 is essential for RAD51-mediated recombination in somatic cells. Absence of 
RAD54 leads to DNA damage hypersensitivity, strong reduction in homologous recombination efficiency and defects in pairing of homologous loci following DSB formation [73-78]. However, beyond the fact that Arabidopsis rad54 plants are fertile, a role for RAD54 in Arabidopsis meiotic recombination has not been assessed. Given its essential role in RAD51-nucleofilament activity and its expression in meiocytes [34,35] we hypothesized that RAD54 may also play an important role in meiotic recombination in plants.

Here, we present a detailed analysis of RAD54 function in meiotic recombination in Arabidopsis. Our data show that absence of RAD54 has no detectable effect on meiotic recombination in otherwise wild-type plants, but that RAD54 becomes essential for meiotic DSB repair in absence of DMC1. In Arabidopsis dmc1 mutants, RAD51 repairs meiotic DSBs but does not produce chiasmata and absence of RAD54 in $d m c 1$ mutants leads to massive chromosome fragmentation (a "rad51-like" phenotype). RAD51 immunolocalization confirms that meiotic RAD51 nucleofilaments are formed (but non-productive) in $d m c 1$ rad54 double mutants. Strikingly, similar analyses show no effect on meiosis of combining $d m c 1$ with the mutants of the RAD51-mediators RAD51B, RAD51D and XRCC2.

Our data demonstrate that RAD54 is required for RAD51-dependent repair of meiotic DSBs in Arabidopsis in the absence of DMC1. We propose that the absence of a detectable meiotic phenotype in rad54 plants is a consequence of RAD51's RAD54-independent, noncatalytic supporting role to DMC1 in meiotic recombination. We cannot exclude the possibility that RAD51-RAD54-dependent recombination plays a minor role in WT meiosis (for instance as a back-up of DMC1), but note that should this be the case, it does so without producing detectable modification of meiotic progression or outcomes. Our findings have several interesting implications for the regulation of the strand invasion step during meiotic recombination in Arabidopsis, which are further discussed.

\section{Results}

\section{RAD54 is essential for somatic DNA repair}

RAD54 is instrumental for homologous recombination in both mitotic and meiotic cells in many organisms (see above). In plants, previous analyses have also demonstrated a role of RAD54 in RAD51-mediated DSB repair in somatic cells, while the observation that rad54-1 Arabidopsis mutant plants are fertile showed that the RAD54 protein does not play an essential role in Arabidopsis meiosis [73-78]. However, the existence of more subtle evidence for meiotic roles of RAD54 has not yet been assessed in plants. In addition to using the previously characterised rad54- 1 allele, we have characterised a second RAD54 T-DNA insertion allele (SALK_124992), which we have named rad54-2 (Fig 1A). The exact genomic structure of the T-DNA insertion in the rad54-2 allele was verified by PCR and sequencing (Fig $1 \mathrm{~A}$ ) and homozygous mutant lines were analysed by RT-PCR to confirm the absence of the respective transcripts (Fig 1B). In rad54-2, the T-DNA is inserted in exon 4 of the RAD54 gene. This insertion is flanked by T-DNA LB sequences in opposite orientations and is associated with a deletion of 11 bp of the RAD54 exon 4 sequence (Fig 1A). No transcript was detected with primers spanning the T-DNA insertion site, confirming the absence of full-length transcript (Fig 1B), although as commonly observed in the insertions, a transcript could be detected in rad54-2 upstream and downstream of the T-DNA insertion. Sequence analysis showed that an in-frame stop codon is present in the upstream T-DNA left border, $24 \mathrm{bp}$ after the chromosome-T-DNA junction (Figs $1 \mathrm{~A}$ and S1). Thus, a protein of the first 285 amino acids (out of 910) of RAD54 fused to 8 amino acids translated from the first $24 \mathrm{nt}$ of the T-DNA LB could potentially be expressed from the rad54-2 allele. If present, this protein would lack all of the described essential domains for RAD54 activity (S1 Fig). 

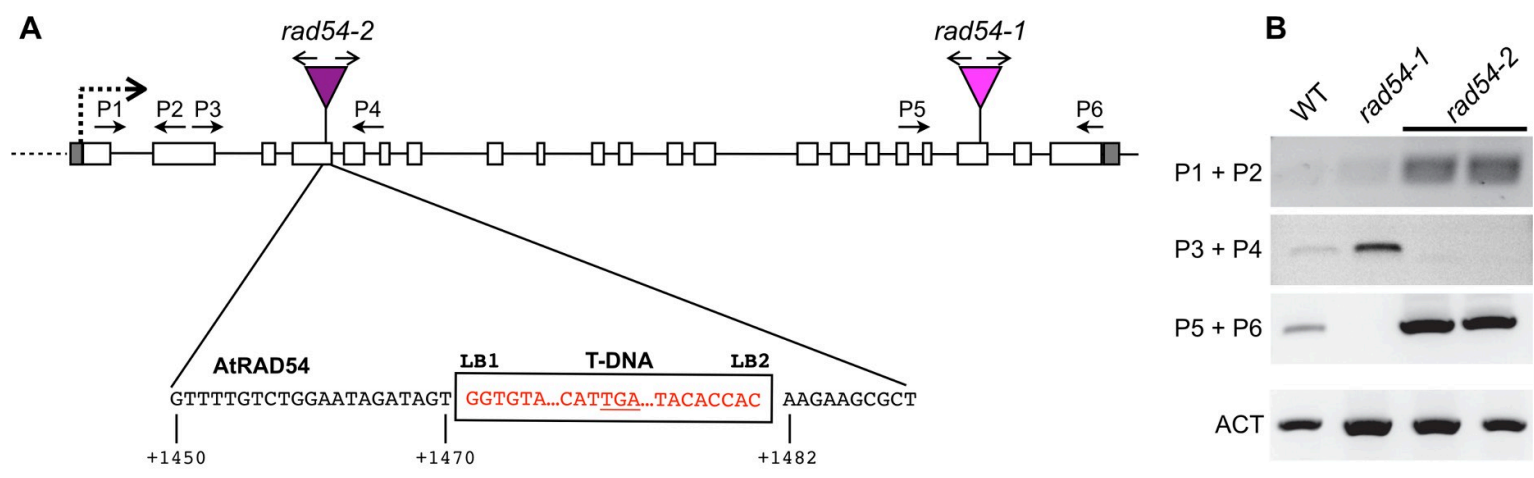

C

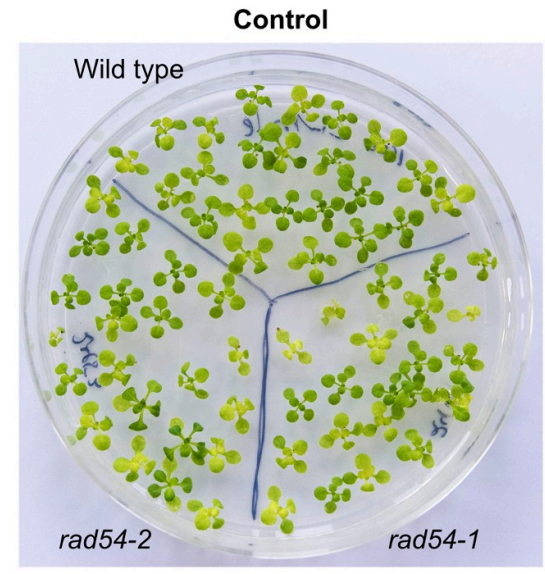

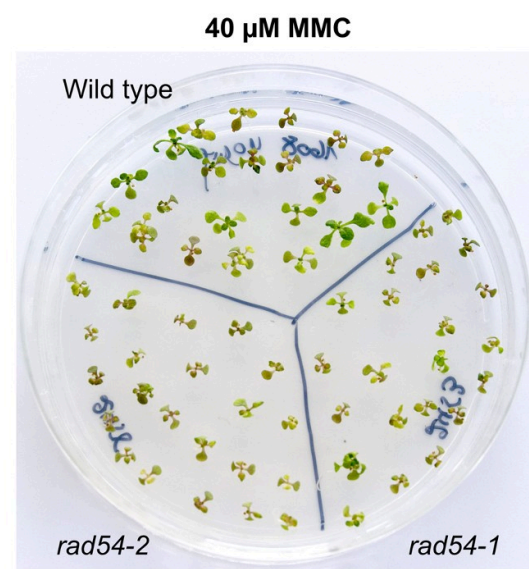

D

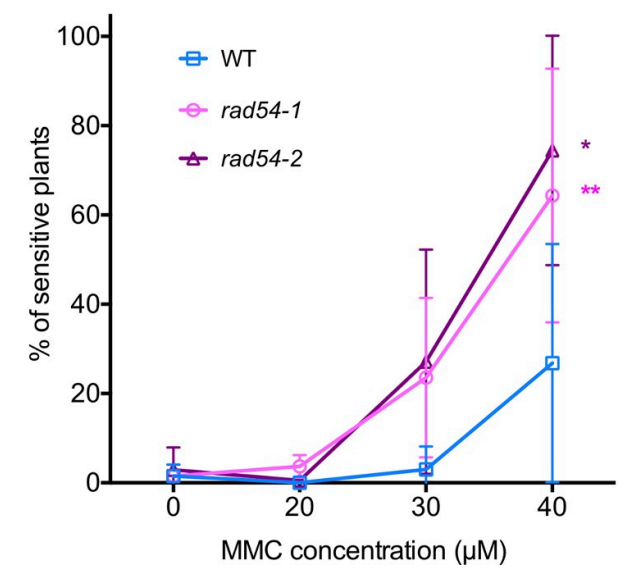

Fig 1. Characterisation of rad54-2 T-DNA insertion mutant and sensitivity to MMC. (A) Structure of AtRAD54 (At3g19210) and the rad54-1 and rad54-2 T-DNA insertion mutant alleles. Boxes show exons (unfilled) and 5' and 3'UTRs (grey fill). The positions of the T-DNA insertions in the two alleles (inverted triangles) is indicated, with arrows above showing orientation of the left borders, and the sequences of the rad54-2 T-DNA/chromosome junctions below. The rad54-2 T-DNA insertion is flanked by two left borders (LB1, LB2) and accompanied by a 11 bp deletion in exon 4 . An in-frame TGA STOP codon in rad54-2 is underlined. Numbering under the sequences is relative to the RAD54 start codon. (B) RT-PCR analyses of transcripts of rad54-1 and rad54-2. Amplification of the actin transcript (ACT) was used as a control for RT-PCR. Positions and orientations of the PCR primers are shown on the diagrams. (C-D) Sensitivity of rad54-1 and rad54-2 plants to MMC. (C) Two-week-old seedlings grown without, or with $40 \mu M$ MMC are shown. (D) Sensitivity of the seedlings was scored after 2 weeks (see Materials and Methods) and the percentages of sensitive plants (plants with 3 true leaves or less) are shown. Symbols are mean \pm SD of at least 3 independent experiments with $\geq 25$ seedlings per genotype per experiment. ( ${ }^{*}<0.05$ and ${ }^{* *}$ $\mathrm{p}<0.005$; paired two-tailed $\mathrm{t}$-test).

https://doi.org/10.1371/journal.pgen.1008919.g001 
The rad54-1 and rad54-2 plants were used to confirm the role of RAD54 in DSB repair and homologous recombination in somatic cells by testing the sensitivity of the mutants to the DNA damaging agent Mitomycin C (MMC; Figs 1C and 1D and S2). MMC is known to form DNA interstrand cross-link adducts, which produce DNA strand breaks in vivo. The importance of homologous recombination in the repair of DNA cross-links has led to the use of MMC hypersensitivity as a test for HR capacity in a number of organisms. In Arabidopsis, this is seen in the MMC hypersensitivity of many homologous recombination-deficient mutants $[26,28,52,76,79]$. As previously shown, rad54-1 plants display clear hypersensitivity to MMC [76] (Figs 1C and 1D and S2). MMC hypersensitivity is also seen in rad54-2 plants, particularly visible at $40 \mu \mathrm{M} \mathrm{MMC} \mathrm{(p-value}>0.05$, paired two-tailed ttests; Figs 1C and 1D and S2) and confirming the importance of RAD54 in homologous recombination in somatic cells.

\section{Absence of RAD54 does not affect meiotic progression}

Meiotic defects are usually reflected in reduced fertility and thus in a reduction in seed number in Arabidopsis [80]. We thus monitored number of seeds per silique in our two rad54 mutant lines and found, as expected, no fertility defects in either rad54-1 or rad54-2 (S3 Fig and S1 Data). The mean seed number per silique was 56 seeds per silique for both $\mathrm{rad} 54-1(\mathrm{n}=40$ siliques) and rad54-2 $(\mathrm{n}=80)$, while wild-type siliques contained on average 58 seeds per silique ( $\mathrm{n}=40$ for RAD54-1 and $\mathrm{n}=60$ for RAD54-2) (S3 Fig and S1 Data). These small differences are not statistically significant ( $p>0.05$; unpaired, two-tailed Mann-Whitney test). In agreement with previous results [76], this confirms that RAD54 is not instrumental for meiosis in plants, notwithstanding its importance in somatic recombination. This conclusion was further supported through cytogenetic analyses of 4',6-diamidino-2-phenylindole (DAPI) stained chromosomes through male meiosis. Wild-type Arabidopsis meiosis has been well described and the major stages are shown in Fig 2. During prophase I, meiotic chromosomes condense, pair, recombine and undergo synapsis. Full synapsis of homologues is seen at pachytene (Fig $2 \mathrm{~A}$ ). Chromosomes further condense and five bivalents (two homologous chromosomes attached by sister chromatid cohesion and chiasmata) are visible at metaphase I (Fig 2B). Each chromosome then separates from its homologue, leading to the formation of two groups of five chromosomes easily visualised at metaphase II (Fig 2C). Meiosis II proceeds and gives rise to 4 balanced haploid nuclei (Fig 2D). In rad54 mutants, meiotic stages appear indistinguishable from the wild-type, resulting in the expected 4 haploid meiotic products (Fig 2E-2L). Thus, meiotic progression is not affected by absence of RAD54.

\section{Absence of RAD54 does not affect crossover recombination rate and interference}

We next sought to analyse more closely the impact of RAD54 on meiotic recombination by measuring meiotic $\mathrm{CO}$ rates in genetic intervals marked by transgenes encoding fluorescent marker proteins expressed in pollen (FTLs; [81,82]). Combined with mutation of the QUARTET1 gene (qrt) which prevents separation of the four pollen grains [83], these FTL lines permit direct measurement of recombination between the linked fluorescent markers by scoring tetrad pollen fluorescence $[81,82]$. We determined $\mathrm{CO}$ rates in two adjacent intervals on chromosomes 1 (I1b and I1c) and 2 (I2f and I2g) in wild-type and rad54-2 mutant plants. In wildtype plants, I1b (1.8 Mb) spans $10.3 \mathrm{cM}$ and I1c $(4.1 \mathrm{Mb}) 22.2 \mathrm{cM}$ (Fig 3 and S1 Table). No difference in recombination frequency was observed for either interval in rad54-2 mutants with 9 $\mathrm{cM}$ and $22.7 \mathrm{cM}$ for I1b and I1c, respectively (Fig 3 and S1 Table). Analyses of two additional intervals, I2f $(0.7 \mathrm{Mb})$ and I $2 \mathrm{~g}(0.4 \mathrm{Mb})$, on chromosome 2 confirmed this result, with no 

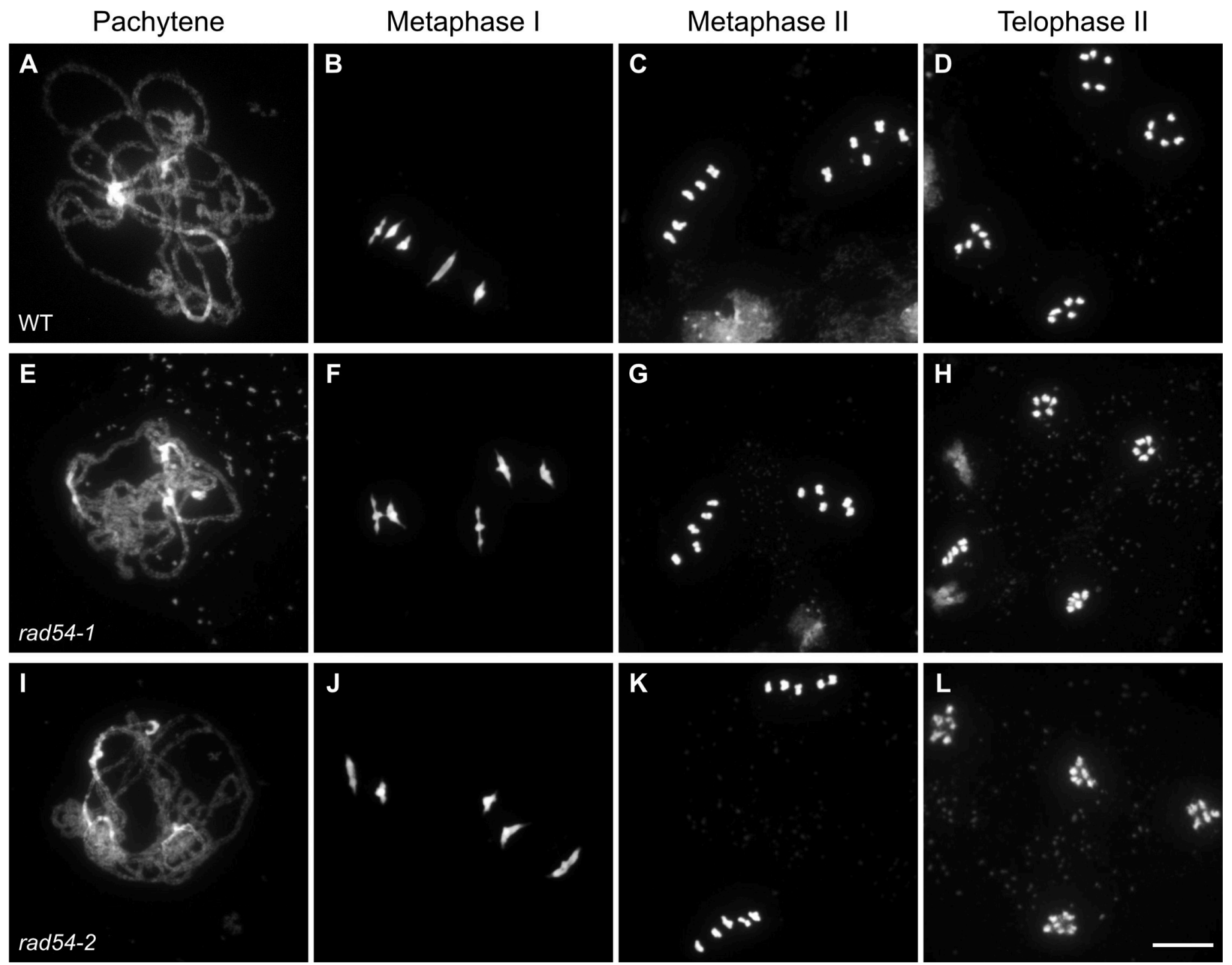

Fig 2. Both rad54-1 and rad54-2 mutants have WT meiosis. Chromosome spreads of male meiocytes in wild type (A-D), rad54-1 (E-H) and rad54-2 (I-L). Pachytene $(\mathrm{A}, \mathrm{E}, \mathrm{I})$; Metaphase I (B,F,J); Metaphase II (C,G,K); Telophase II (D,H,L). Chromosomes were spread and stained with DAPI. (Scale bar $=10 \mu \mathrm{m})$.

https://doi.org/10.1371/journal.pgen.1008919.g002

significant difference in recombination frequency observed between the wild-type and rad54-2 mutants ( $6.8 \mathrm{cM}$ to $6.9 \mathrm{cM}$ for I2f and $4.3 \mathrm{cM}$ to $4.9 \mathrm{cM}$ for I2g; Fig 3 and S1 Table). We obtained similar results for rad54-1 mutant plants with $6.5 \mathrm{cM}$ and $4.7 \mathrm{cM}$ in I2f and I2g, respectively (S4 Fig and S1 Table). In accordance with these results, we found a similar interference ratio (IR) in wild-type plants and rad54 mutants for both intervals (IR I1bc: 0.35 in wild-type and 0.36 in rad54-2; IR I2fg: 0.09 in wild-type, 0.1 in rad54-1 and 0.1 in rad54-2; p > 0.05, z-test; S1 Table).

Thus, absence of RAD54 does not affect meiotic CO rates in at least 4 different intervals on 2 chromosomes. These results were further confirmed genome-wide through counting chiasmata in metaphase I of wild-type, rad54- 1 and rad54-2 male meiocytes, which show means of $9.6(\mathrm{SD}=1.3 ; \mathrm{n}=19), 9.6(\mathrm{SD}=1.5 ; \mathrm{n}=25)$ and $9.1(\mathrm{SD}=1 ; \mathrm{n}=19)$ chiasmata per meiosis, respectively ( $\mathrm{p}>0.05$, unpaired two-tailed t-tests). 
A

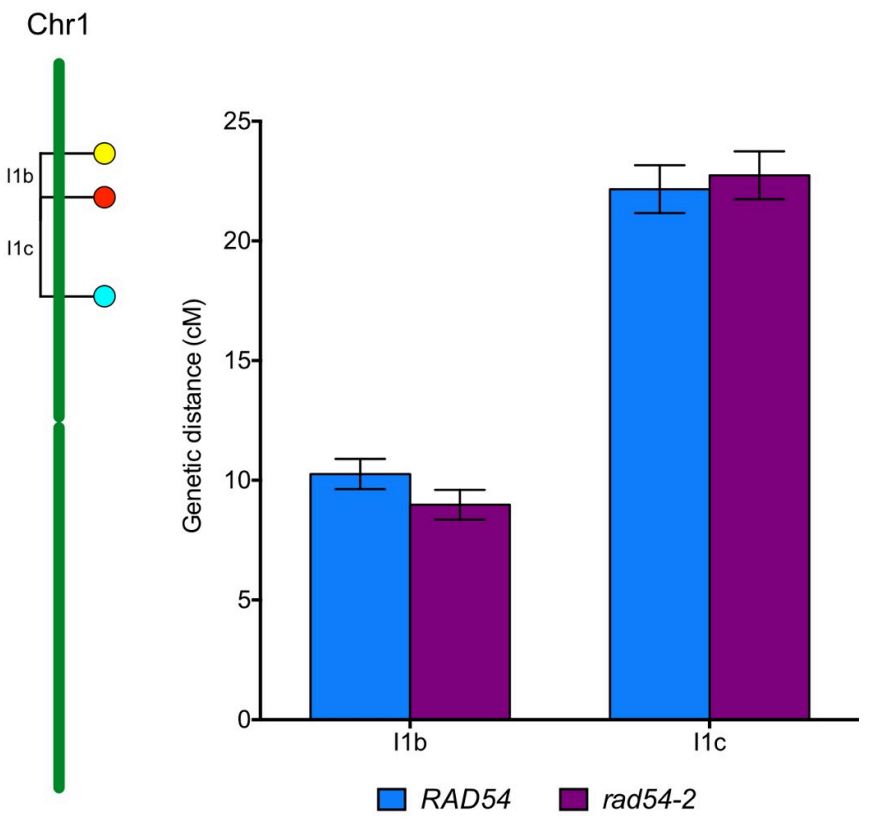

B

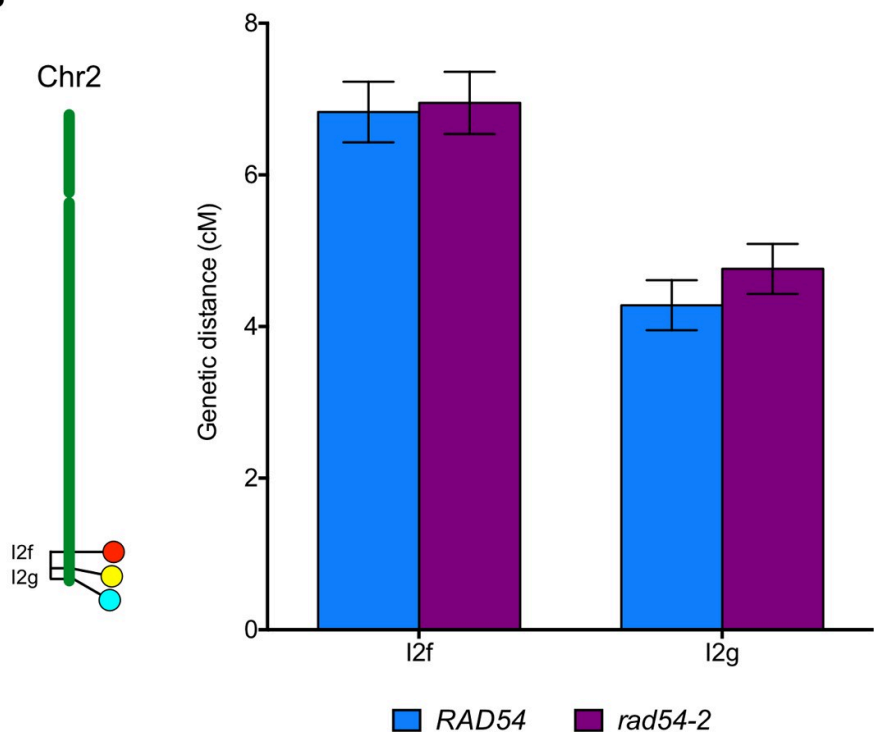

Fig 3. Crossing-over is not affected in rad54-2 mutant meiosis. Genetic distances (in centiMorgans, $\mathrm{cM}$ ) measured from fluorescent tetrad analyses in marked intervals on (A) chromosome 1 (I1b and I1c) and (B) chromosome 2 (I2f and $\mathrm{I} 2 \mathrm{~g}$ ). Bars indicate mean \pm SD. On all intervals, WT and rad54 do not significantly differ ( $\mathrm{p}>0.05 ; \mathrm{Z}$-test).

https://doi.org/10.1371/journal.pgen.1008919.g003

\section{RAD54 is essential for RAD51-dependent repair of meiotic DSB in absence of DMC1}

These data confirm that RAD54 is not required for meiotic recombination in Arabidopsis, an a priori surprising conclusion given the importance of RAD54 in homologous recombination 
(see Introduction). Data from budding yeast have shown that RAD54 is not essential for meiotic recombination in presence of DMC1 and the DMC1-specific RAD54 homologue Rdh54 (Tid1) $[53,63,66-68]$. Instead, interaction of RAD54 with RAD51 is constrained during meiotic recombination in yeast and this represents a key point in the mechanisms leading to downregulation of RAD51 activity in meiosis $[53,60]$. The RAD51-RAD54 pathway however becomes essential for sister chromatid repair in absence of DMC1 $[62,63]$. We thus hypothesized that RAD54 may be essential for RAD51-mediated repair of meiotic DSB in Arabidopsis. To test this hypothesis, we analysed meiosis in the absence of DMC1. Meiosis in Arabidopsis $d m c 1$ mutants has been well described $[84,85]$ and the major stages are summarized in Fig 4 . Absence of DMC1 leads to asynapsis and lack of inter-homologue CO. However intact univalents are observed in metaphase I owing to DSB repair by RAD51, most probably using sister chromatid donors (Fig 4E-4H).

In striking contrast, analyses of $d m c 1$ rad54 double mutants show an absence of synapsis (Fig 4) and massive chromosome fragmentation (Fig 4I-4P), a meiotic phenotype analogous to that seen in rad51 mutants (Fig 4Q-4T). Absence of synapsis in $d m c 1$ rad54 double mutants was confirmed by immunolocalization of the synaptonemal complex (SC) axial element protein ASY1 and the SC transverse filament protein ZYP1 (S5 Fig). Thus, in the absence of DMC1, RAD51-dependent meiotic HR repair indeed depends upon the presence of RAD54 (Fig 4I-4P). This effect is confirmed by the significant reduction of fertility caused by the absence of RAD54 in $d m c 1$ mutant plants (S6 Fig and S1 Data). Thus, beyond supporting DMC1, either RAD51 does not play an (or plays only a minor) active role in meiotic recombination in WT plants, or its role is able to be compensated for by DMC1 without producing detectable modification of meiotic progression or outcomes.

To confirm this RAD54 requirement of RAD51-dependent recombination in meiosis, we crossed the rad54 mutants with the Arabidopsis $s d s$ mutants. SDS is a meiosis-specific cyclinlike protein that is instrumental for normal DMC1 focus formation/stabilization, meiotic DSB repair with the homologous chromosome and CO formation [86-90]. Mutant plants lacking SDS have thus a dmc1-like phenotype, with absence of detectable DMC1 foci and presence of intact univalents, pointing to RAD51 repairing meiotic DSBs in $s d s$ mutants (as is the case in $d m c 1$ meiosis). As expected, our analysis of $s d s$ rad54 meiosis does show increased numbers of meiosis showing chromosome fragmentation (S7 Fig), however the effect is noticeably less pronounced than that seen in $d m c 1$ rad54 meiosis. The reduced penetrance of the $s d s$ rad54 meiotic phenotype relative to that of $d m c 1$ rad54 points to a (residual?) capacity of DMC1 to catalyse DSB repair in rad54 sds mutants, or that the RAD54-dependency of RAD51 in meiosis is partially alleviated in absence of SDS.

\section{Absence of RAD54 does not affect RAD51 focus formation during meiosis}

RAD54 is an essential cofactor for regulating RAD51 activity and has been implicated in both early and late steps of the HR pathway (see Introduction). Our data show that RAD54 is required for repair of meiotic DSB by RAD51 in Arabidopsis. Furthermore, that RAD54 is not required in the presence of DMC1 suggests that the RAD54-dependent meiotic role of RAD51 intervenes downstream of that of the RAD51 nucleofilament in supporting DMC1 activity. This being so, it would follow that meiotic RAD51-nucleofilament formation would be RAD54-independent. We thus quantified meiotic RAD51 focus formation as a proxy for RAD51 nucleofilament formation in these plants. We performed co-immunolocalization of RAD51 and the axis protein, ASY1, in wild-type, rad54, $d m c 1$, and $d m c 1$ rad54 meiocytes and counted the number of RAD51 foci throughout early prophase I (Fig 5). In wild-type meiocytes, we observed a mean of $91 \pm 29$ RAD51 foci $( \pm$ SD, $n=35)$. Similar numbers of RAD51 


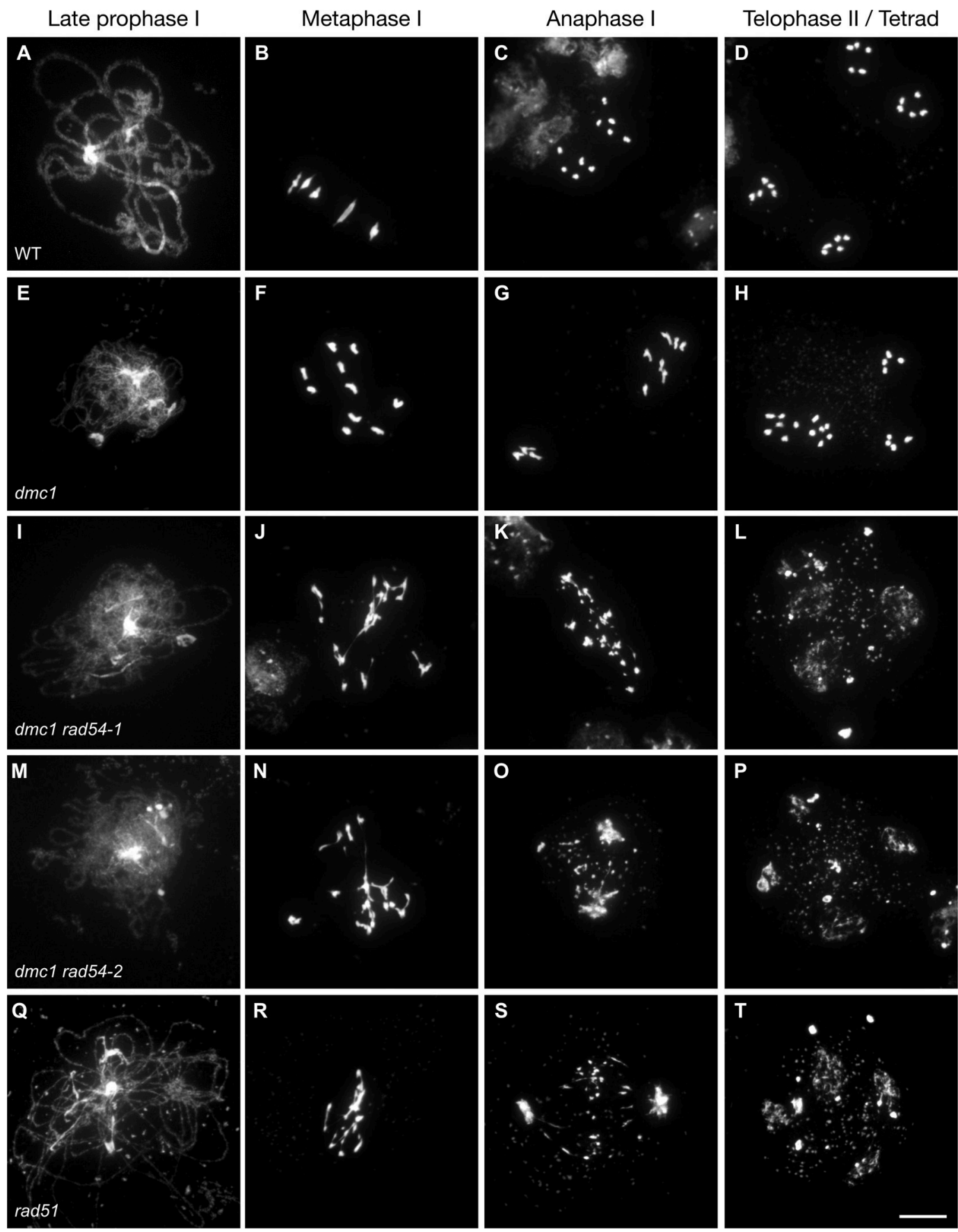

Fig 4. Absence of RAD54 leads to chromosome fragmentation in $\mathbf{d m c 1}$ meiosis. Male meiosis is shown in (A-D) wildtype, (E-H) $d m c 1$, (I-L) $d m c 1$ rad54-1, (M-P) $d m c 1$ rad54-2, and rad51 (Q-T). Chromosome spreads at late prophase I (A,E, I,M,Q), Metaphase I (B,F,J,N,R), Anaphase I (C,G,K,O,S) and Telophase II/Tetrad (D,H,L,P,T). Chromosomes were spread and stained with DAPI. (Scale bar $=10 \mu \mathrm{m})$.

https://doi.org/10.1371/journal.pgen.1008919.g004

foci were observed in rad54 $(89 \pm 18, \mathrm{n}=22)$ and $d m c 1(97 \pm 26, \mathrm{n}=50)$ single mutant plants and importantly, the numbers of RAD51 foci were also unchanged in $d m c 1$ rad54 double mutants $(94 \pm 16, \mathrm{n}=56)($ Fig 5). 
A
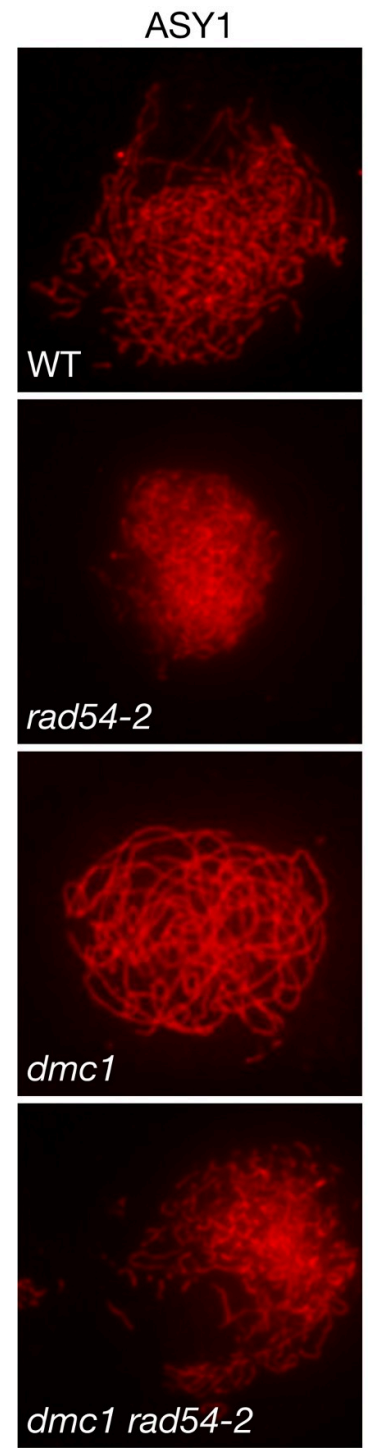
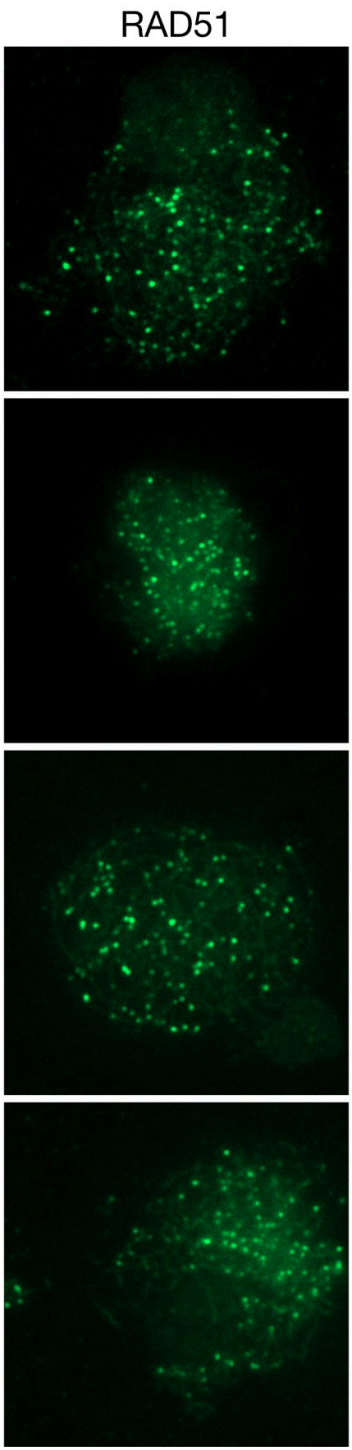
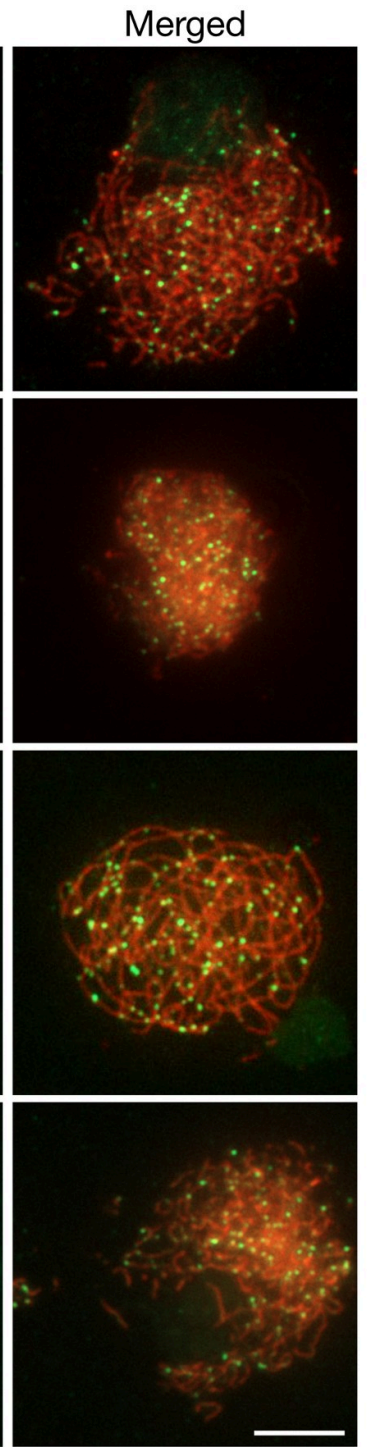

B

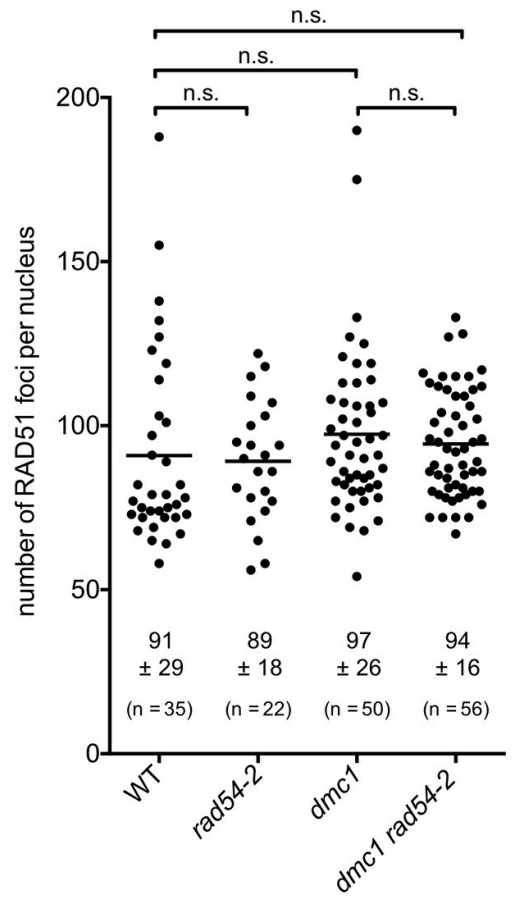

Fig 5. Absence of RAD54 does not affect numbers of meiotic RAD51 foci. (A) Co-immunolocalization of RAD51 (green) and the chromosome axis protein ASY1 (red) on leptotene/zygotene meiotic chromosome spreads. (Scale Bars: $5 \mu \mathrm{m}$ ). (B) Quantification of RAD51 foci per positive cell through early prophase I in wild-type, rad54, $d m c 1$, and $d m c 1$ rad54-2 mutants. Means \pm SD are indicated. n.s.: not significantly different ( $\mathrm{p}$-value $>0.05$, Kruskal-Wallis test).

https://doi.org/10.1371/journal.pgen.1008919.g005

To test for a possible role for RAD51-mediated recombination late in prophase, we performed co-immunolocalization of ZYP1 and RAD51 in pachytene cells of rad54 single mutants (S8 Fig). Similar numbers of RAD51 foci were observed in wild-type (16.8 \pm 11 , $\mathrm{n}=60)$ and rad54-2 mutant plants $(13.1 \pm 8, \mathrm{n}=40)$ (S8 Fig and S1 Data). Thus, absence of RAD54 does not detectably affect numbers of meiotic RAD51 foci in late prophase I. Given the role of RAD54 in disassembling RAD51-ssDNA nucleofilaments [74,75,91,92], it might have been expected to find more RAD51 foci in the $d m c 1$ rad54 meioses. However, with the absence of synapsis and significant chromosomal fragmentation that occurs in this mutant, it isn't possible to draw meaningful conclusions concerning RAD51 focus numbers beyond leptotene-early zygotene in these plants. Notwithstanding, this does not affect the conclusion that 
apparently normal numbers of RAD51 nucleofilaments are formed in $d m c 1$ rad54 double mutants, but that these are not productive for recombination. Hence, these results fully concord with the conclusion (above) that RAD54 acts downstream of meiotic RAD51 nucleofilament formation. In accordance with RAD54's known role in supporting the activity of the mitotic RAD51 nucleofilament, this meiotic role is presumably in facilitating RAD51-dependent invasion of the donor DNA duplex [93].

\section{RAD51-dependent repair of meiotic DSB does not require RAD51 paralogues RAD51B, RAD51D and XRCC2}

RAD51 nucleofilament activity is also extensively regulated by the RAD51 paralogues (see Introduction). In Arabidopsis, RAD51C and XRCC3 are essential for meiotic recombination, with absence of either leading to massive chromosome fragmentation [24-26,28,29]. In contrast, the roles of RAD51B, RAD51D and XRCC2 in meiosis are less clear and their absence does not lead to any obvious visible meiotic defects $[26,41,42]$. They are however expressed in meiotic tissues [33-35] and we have previously reported an increased meiotic recombination rate in Arabidopsis xrcc2 (and to a lesser extent rad51b) mutants in two genetic intervals [41], suggesting potential roles for these paralogues during meiosis.

It thus appears possible, in analogy to RAD54 (above), that the absence of visible meiotic phenotype in rad51b, rad51d or xrcc 2 mutants could simply be a consequence of RAD51 strand-invasion activity not being required for meiotic recombination in the presence of DMC1. We thus sought to test the impact of RAD51 paralogues in RAD51-dependent meiotic DSB repair by analysing meiotic progression in their absence in a $d m c 1$ mutant background (Fig 6). As described above, $d m c 1$ mutants are characterized by strong synaptic defects and lack of CO (Fig 6A-6C). However, meiotic DSB are still repaired as seen in the presence of intact achiasmate univalents at metaphase I (Fig 6B), that segregate randomly at anaphase I (Fig 6C). These analyses did not show any detectable effects of the absence of RAD51B, RAD51D or XRCC2 in the $d m c 1$ mutant background (Fig 6D-6L). In contrast, the expected chromosome fragmentation is observed in $x r c c 3$ mutant meiosis [28] and this is not affected by the additional absence of DMC1 (Fig 6M-6O). Thus, despite being expressed in meiotic cells and playing key roles in RAD51 activity in somatic cells, RAD51B, RAD51D and XRCC2 are not required for RAD51-dependent meiotic DSB repair in Arabidopsis.

\section{Discussion}

Here, we provide evidence that Arabidopsis RAD54 is essential for meiotic double-strand break repair mediated by RAD51. This requirement for RAD54 is not observed in the presence of DMC1 as most (all?) meiotic DSBs are repaired by DMC1, with RAD51 playing a supporting role to $\mathrm{DMC} 1$ in this process $[51,52,61]$. In the absence of DMC1 however, RAD51 catalyses the repair of meiotic DSB, leading to segregation of intact univalent chromosomes at meiotic anaphase I. Thus, absence of Arabidopsis RAD54 has no detectable effect on meiotic recombination in otherwise wild-type plants, but becomes essential for RAD51-dependent meiotic DSB repair in the absence of DMC1 (as seen in $d m c 1$ and $s d s$ mutants).

That this effect is not simply a reflection of a "mitotic" RAD51-dependent recombination context in $\mathrm{dmcl}$ meiosis is seen in the results of equivalent analyses with three RAD51 paralogue proteins, XRCC2, RAD51B and RAD51D, essential positive regulators of homologous recombination in somatic cells (reviewed in [11-13]). Mutants of these key RAD51-mediator proteins have no detectable meiotic phenotypes, beyond a mild meiotic hyper-rec phenotype reported for $x r c c 2$ and $r a d 51 b$ plants [26,41,42]. We report here that, in striking contrast to RAD54, the RAD51 paralogues RAD51B, RAD51D and XRCC2 are not required for 

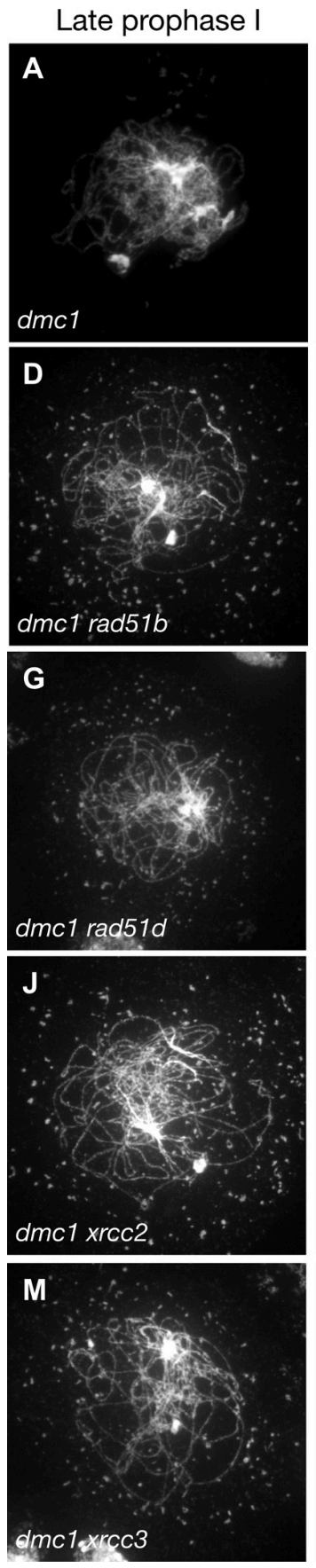

Metaphase I
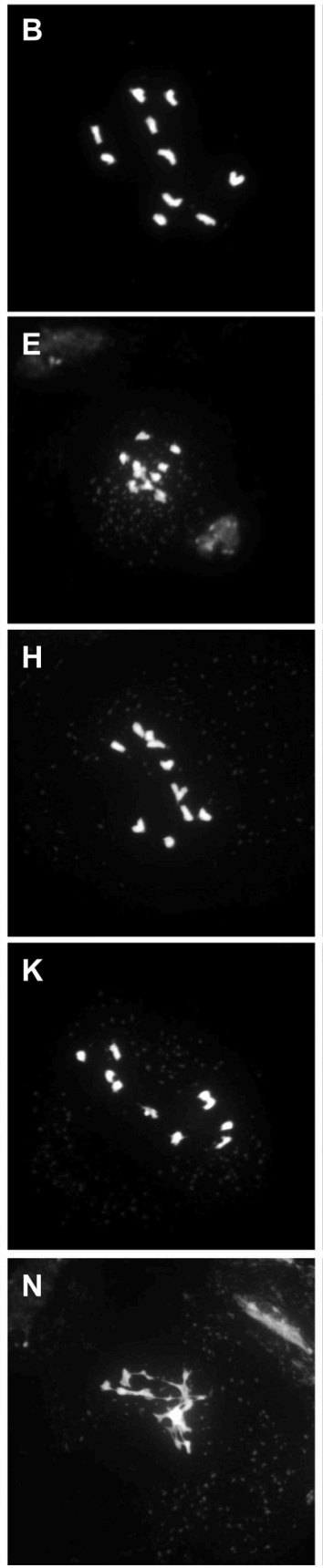

Anaphase I
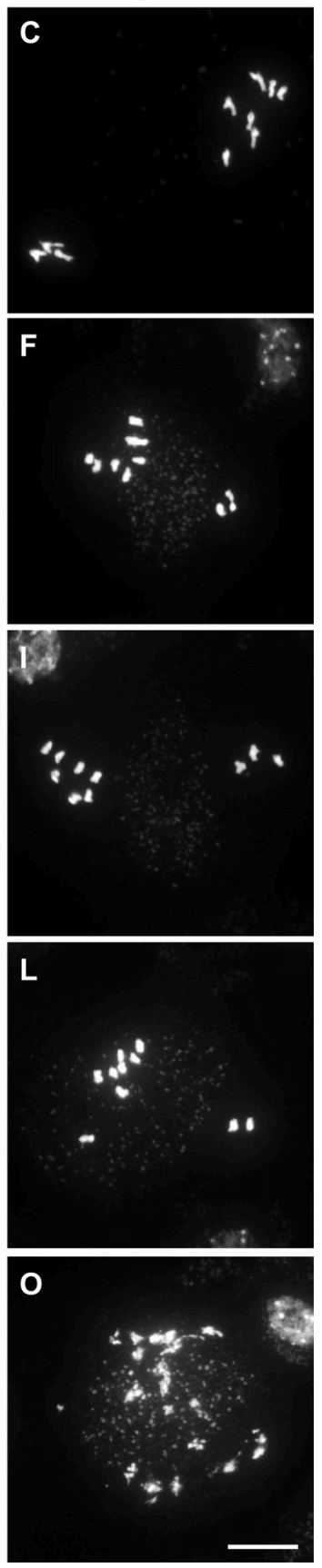

Fig 6. Absence of RAD51B, RAD51D or XRCC2 does not affect $\boldsymbol{d} m \boldsymbol{c} 1$ meiosis. Male meiosis is shown in (A-C) $d m c 1$, (D-F) $d m c 1$ rad51b, (G-I) $d m c 1$ rad51d, (J-L) $d m c 1 x r c c 2$, and $d m c 1 x r c c 3$ (M-O). Chromosome spreads at (A,D, G,J,M) late prophase I, $(\mathrm{B}, \mathrm{E}, \mathrm{H}, \mathrm{K}, \mathrm{N})$ Metaphase I, $(\mathrm{C}, \mathrm{F}, \mathrm{I}, \mathrm{L}, \mathrm{O})$ Anaphase I. Chromosomes were spread and stained with DAPI. (Scale bar $=10 \mu \mathrm{m})$.

https://doi.org/10.1371/journal.pgen.1008919.g006

RAD51-dependent meiotic DSB repair in Arabidopsis, despite being expressed in meiotic cells and playing key roles in somatic RAD51 activity.

RAD54 is a required cofactor for RAD51 activity and is thus instrumental for both mitotic and meiotic recombination in organisms lacking the meiosis-specific recombinase DMC1 
[47-49]. The role of RAD54 in meiosis is however less clear in organisms expressing DMC1. Studies in budding and fission yeast have shown that Rad54 plays a relatively minor role in meiotic recombination [62-68]. This is however due to the presence of a second RAD54 homologue, Rdh54/Tid1. While both rad54 and $r d h 54$ mutants form viable spores (albeit at reduced frequency), the rad54 $r d h 54$ double mutant rarely produces spores and is severely defective in meiotic recombination [64,66-68]. These data reveal overlapping roles of Rad54 and Rdh54/Tid1 in meiotic recombination. In addition, Rdh54 preferentially acts with Dmc1 to promote inter-homologue recombination, whereas Rad54 preferentially stimulates Rad51-mediated strand invasion for sister chromatid repair [62,63,66,70]. It is thus suggested that Rad54 is involved with Rad51 in sister chromatid repair of residual meiotic DSBs and this is in accordance with the recent demonstration of Rad51 being essential only to support Dmc1 and to repair residual DSBs after IH recombination is complete [51,69,94,95].

In multicellular eukaryotes, evidence for a role of RAD54 homologues in meiosis however remains to be demonstrated. Mammals have two known RAD54 family members, RAD54 and RAD54B, neither of which appear to have important functions in meiosis, as mice lacking RAD54, RAD54B or both exhibit no, or only minor meiotic recombination defects [71,72]. Our data demonstrate that RAD54 is essential for RAD51-mediated repair of meiotic DSBs in $d m c 1$ Arabidopsis. SDS is a meiosis-specific cyclin-like protein essential for normal DMC1 activity. In particular, absence of SDS leads to defects in DMC1 focus formation/stabilization, meiotic DSB repair with the homologous chromosome and CO formation [86-90]. Analysis of sds rad54 double mutants reveals chromosome fragmentation defects in these mutants, however these are considerably less frequent that those seen in the absence of DMC1 ( $d m c 1$ mutant). We conclude that the expected impact of absence of RAD54 is seen in $s d s$ meiosis, but that the phenotype is considerably less penetrant than that seen in the absence of DMC1 protein. These results thus confirm the role of RAD54 in meiotic DSB repair. To our knowledge this is the first evidence of a clear meiotic role of RAD54 in a DMC1-expressing multicellular eukaryote. In Arabidopsis $d m c 1$ mutants, DSBs are repaired without formation of interhomologue $\mathrm{CO}$ and this concords with the suggestion that RAD51 repairs meiotic DSB using the sister chromatid template $[84,85,96]$. Although this essential role is only observed in the absence of DMC1, we cannot exclude that the RAD51/RAD54 DSB repair pathway is also active (albeit weakly) in wild-type plants, possibly to repair excess DSBs as has been shown in yeast $[62,63]$. Whether this pathway also exists in wild-type plants, remains however to be demonstrated.

Another conclusion inferred from our data is that Arabidopsis RAD54 is not necessary for DMC1 activity, either alone or as a RAD51 cofactor. That absence of RAD54 has no detectable effect on meiotic recombination in the presence of DMC1 tells us that RAD51's function as an essential accessory factor for DMC1 is RAD54-independent. This conclusion concords with the reported absence of interaction between Arabidopsis RAD54 and DMC1 [76]. Yet, the DMC1 nucleofilament must perform homology search and strand invasion and this requires ATP-dependent DNA translocases (reviewed in [44,46,97]). We thus hypothesize that there exists a second, as yet unknown, DMC1-specific RAD54 homologue in plants. RAD54 is a SWI2/SNF2-remodelling factor that belongs to the SF2 helicase family, a number of which are encoded by the Arabidopsis genome $[76,78,98]$, but to date only RAD54 (this work) has been found to play a role in meiosis.

Control of Rad51/Rad54 complex formation is used to downregulate Rad51 activity during meiosis in budding yeast, presumably to favour interhomolog recombination driven by Dmc1 $[8,51,55,56,61]$. This downregulation is largely achieved through preventing Rad51/Rad54 complex formation via two pathways involving two meiosis-specific proteins: the RAD51-binding protein Hed1 and the Mek1 kinase (which phosphorylates both RAD54 and Hed1) 
[53-55,57,58,60]. Briefly, Mek1-mediated phosphorylation of RAD54 weakens

RAD51-RAD54 interaction $[53,55]$ and binding of Hed1 to RAD51 also prevents association of RAD54 [54,55,57,58,60]. Interestingly, no apparent Hed1 or Mek1 orthologues have been identified in higher eukaryotes and in particular in plants. Several reports suggest that RAD51 is also down-regulated in Arabidopsis meiosis [52,84,85,96,99,100], but the evidence for this remains indirect. Thus, whether RAD51 strand exchange activity is down-regulated during meiosis in higher organisms and if so, how this is achieved, is not clear. The absence of meiotic phenotype of Arabidopsis rad54 mutants, together with the demonstration of the RAD54-dependence of meiotic RAD51 activity (in the absence of DMC1), supports the idea of a hypothetical RAD54-dependent control of RAD51 activity through modulation of the RAD54/ RAD51 interaction. It also, however, invites speculation concerning whether it is necessary to invoke such a downregulation to explain numbers of $\mathrm{CO}$ vs non-CO recombination events in plants, and very likely in vertebrates. Previous work has shown that DMC1 is capable of catalysing repair of all meiotic DSB in Arabidopsis in strand-invasion mutants of RAD51 [52,99], or as shown here, by blocking RAD51 activity through the absence of RAD54. In both of these contexts, no evidence of alteration of numbers nor distribution of meiotic recombination has been found.

In conclusion, we present here an essential role for RAD54 in supporting meiotic RAD51-mediated DSB repair in the absence of DMC1 in Arabidopsis. In striking contrast, testing of three other key RAD51 mediator mutants ( $r a d 51 b$, rad51d, $x r c c 2)$ did not reveal any detectable impact on $d m c 1$ meiosis, notwithstanding the fact that they are, like RAD54, needed for RAD51-dependent recombination in somatic cells. This RAD54-dependent, RAD51-mediated meiotic DSB repair is thus not the reflection of a simple "mitotic-like" RAD51 DSB repair in meiocytes lacking DMC1, but points to RAD54 mainly acting downstream of the role of the RAD51 nucleofilament in supporting meiotic DMC1-mediated recombination. It will be of particular interest to further study in which context this pathway is activated in wild-type meiosis and also whether a similar pathway exists in other organisms outside the fungal taxa. Although further studies are needed to confirm whether (and how) RAD51 strand-invasion activity is downregulated during meiosis in plants, we speculate that this could be achieved through prevention of RAD54/RAD51 interaction, and/or via helicases dissociating precocious strand-invasion between sister chromatids, as has recently been shown in budding yeast [101].

\section{Materials and methods}

\section{Plant material and growth conditions}

All Arabidopsis thaliana plants used in this study were in the Columbia background. Seeds of the rad54-2 (SALK_124992) [102] T-DNA insertion mutant were obtained through the Nottingham Arabidopsis Stock Centre and characterised in this study. For other mutants, we used the following alleles: rad54-1 [76], dmc1-2 [85], rad51-1 [103], rad51b-1 [26], rad51d-3 [41] and $x r c c 2-1$ [26]. Fluorescent-Tagged lines (FTLs) were: I1bc (FTL567-YFP/ FTL1262-DsRed2/FTL992-AmCyan/qrt1-2), and I2fg (FTL800-DsRed2/FTL3411-YFP/ FTL3263-AmCyan/qrt1-2) [81].

Seeds were stratified in water at $4{ }^{\circ} \mathrm{C}$ for 2 days and grown on soil in a growth chamber. For in vitro culture, seeds were surface sterilised for 5 min with 75\% Ethanol, 0.05\% SDS, rinsed with $95 \%$ Ethanol for $5 \mathrm{~min}$ and air-dried. Sterilised seeds were then sown on halfstrength Murashige and Skoog (MS) medium, stratified at $4^{\circ} \mathrm{C}$ for 2 days and placed in a growth cabinet. All plants were grown under $16 \mathrm{~h}$ light $/ 8 \mathrm{~h}$ dark cycles at $23^{\circ} \mathrm{C}$ and $60 \%$ relative humidity. 


\section{Molecular characterization of rad54-2 T-DNA insertion mutants}

The rad54-2 (SALK_124992) mutant was genotyped using primers P1 and P2 to detect the wild-type loci and primers P1, P2, and Lbal (SALK T-DNA Left Border specific primer) were used to detect the T-DNA insertion allele. The junctions of the T-DNA insertion in the RAD54 locus (AT3G19210) were amplified by PCR and verified by DNA sequencing.

For semi-quantitative RT-PCR, total RNA was extracted from young buds of wild-type, rad54-1 and rad54-2 plants using RNeasy Plant mini Kit (QIAGEN), following the manufacturer's instructions. $2 \mu \mathrm{g}$ RNA were treated with RQ1 RNase-free DNase (Promega) followed by reverse transcription using M-MLV Reverse Transcriptase (Promega) according to the manufacturer's instructions. PCR amplifications were eventually performed in homozygous lines showing the absence of full-length RAD54 transcripts (Fig 1).

\section{Mitomycin C sensitivity assays}

For the MMC sensitivity assay, seeds were surface-sterilised and sown onto solid medium (half strength Murashige and Skoog salts, $1 \%$ sucrose, $0.8 \%$ agar) supplemented with $0,20,30$ or $40 \mu \mathrm{M}$ Mitomycin C (SIGMA). Seeds were stratified in the dark for 2 days at $4^{\circ} \mathrm{C}$, transferred to a growth cabinet and grown for two weeks. Sensitivity was then analysed in two-week-old seedlings by counting the number of true leaves as previously described [28]. Plants with more than three true leaves were considered as resistant. In each case, the number of leaves was counted on at least 25 seedlings in three to five independent experiments.

\section{Recombination measurement using Fluorescent-Tagged Lines (FTL) tetrad analysis}

We used Fluorescent Tagged Lines to estimate male meiotic recombination rates at two pairs of genetic intervals: I1bc on chromosome 1 and I2fg on chromosome 2. For each experiment, heterozygous plants for the linked fluorescent markers were generated and siblings from the same segregating progeny were used to compare the recombination frequency between different genotypes. Slides and fluorescent tetrad analysis were performed as described by Berchowitz and Copenhaver [81]. Tetrads were counted and attributed to specific classes (A to L). Genetic distances of each interval were calculated using Perkins equation as follows: $X=100$ $[(1 / 2$ Tetratype + 3Non-Parental Ditype $) / n]$ in $\mathrm{cM}$.

The Interference Ratio (IR) was calculated as described previously [81]. Briefly, for two adjacent intervals I1 and I2, two populations of tetrads are considered: those with at least one $\mathrm{CO}$ in $\mathrm{I} 2$ and those without any CO in I2. Genetic distance of I1 is then calculated for these two populations using the Perkins equation, i.e. $X 1$ (I1 with CO in I2) and X2 (I1 without a $\mathrm{CO}$ in I2). The Interference Ratio is thus defined as $\mathrm{IR}=X 1 / X 2$. An IR ratio $<1$ reveals the presence of interference while an IR ratio close to 1 reveals absence of interference. The Stahl Lab Online Tools was used for statistical analyses of the data.

\section{Arabidopsis male meiotic chromosome spreads}

Meiotic chromosome spreads were prepared according to [104]. Whole inflorescences were fixed in ice-cold ethanol/glacial acetic acid (3:1) and stored at $-20^{\circ} \mathrm{C}$ until further use. Immature flower buds of appropriate size were selected under a binocular microscope and incubated for 75-90 min on a slide in $100 \mu \mathrm{l}$ of enzyme mixture (0.3\% w/v cellulase (Sigma), $0.3 \% \mathrm{w} / \mathrm{v}$ pectolyase (Sigma) and $0.3 \%$ cytohelicase (Sigma)) in a moist chamber at $37^{\circ} \mathrm{C}$. Each bud was then softened for 1 minute in $20 \mu \mathrm{l} 60 \%$ acetic acid on a microscope slide at $45^{\circ} \mathrm{C}$, fixed with 
ice-cold ethanol/glacial acetic acid (3:1) and air dried. Slide were mounted in Vectashield mounting medium with DAPI (1.5 $\mu$ g. $\mathrm{ml}^{-1}$; Vector Laboratories Inc.).

\section{Immunolocalization of meiotic proteins in pollen mother cells (PMCs)}

Spreads of PMCs for immunolocalization of RAD51, ASY1 and ZYP1 were performed as described previously [105]. Primary antibodies used for immunostaining were: anti-ASY1 raised in guinea Pig (1:500) [106] anti-RAD51 raised in rat (1:500) [107], and anti-ZYP1 raised in rabbit (1:500) [108]. Secondary antibody: anti-rat Alexa fluor 488; anti-rat Alexa fluor 594, anti-guinea pig $\mathrm{Cy} 3$, and anti-rabbit Alexa fluor 488 were used at 1:100 dilution.

\section{Microscopy}

All observations were made with a motorised Zeiss AxioImager.Z1 epifluorescence microscope (Carl Zeiss AG, Germany) driven by the ZEN Pro software (Carl Zeiss AG, Germany). Photographs were taken with an AxioC.am Mrm camera (Carl Zeiss AG, Germany) and Zeiss filter sets adapted for the fluorochromes used. Image stacks were captured in three dimensions $(\mathrm{x}, \mathrm{y}, \mathrm{z})$ and further processed and adjusted for brightness and contrast on ZEN Pro and ImageJ/FIJI software. RAD51 foci were counted on collapsed z-stack projections by using counting tool of the ZEN Pro software.

\section{Supporting information}

S1 Fig. Sequence of RAD54/T-DNA junction in rad54-2 allele and corresponding putative predicted protein. (A) pairwise alignment between AtRAD54 coding sequence (cds) and sequence from T-DNA left border amplification at the T-DNA insertion site in the rad54-2 allele. An in-frame TGA stop codon is highlighted in cyan. T-DNA insertion derived nucleotides deletion is highlighted in grey. (B) Pairwise alignment of the Arabidopsis RAD54 protein and the putative predicted protein from the rad54-2 allele. Alignment was generated using clustalOmega. Numbers indicate amino acid positions. Under the sequences, asterisks, colons and full stops indicate identical, conserved and semi-conserved residues, respectively. The seven conserved ATPase motifs are indicated with black boxes and red roman numerals. These motifs define the two RecA-like domains (parts defined by green and blue lines, respectively), which constitute the "core" translocation motor domains. If translated, the truncated protein from the rad54-2 allele would lack these two recA-like domains.

S2 Fig. Sensitivity of rad54-1 and rad54-2 plants to MMC. Shown are representative photographs of two-week-old seedlings grown without or with the indicated concentrations of MMC.

S3 Fig. Fertility of rad54-1 and rad54-2 mutants. (A) pictures of wild-type and rad54 mutant siliques. (B) Number of seeds per silique in Wild-type, rad54-1 and rad54-2 mutants. Each point represents the number of seeds in one silique. Bars indicate mean \pm SD. n.s.: not significantly different. $\mathrm{P}>0.05$ (unpaired, two-tailed Mann-Whitney test).

(TIFF)

S4 Fig. Genetic recombination in wild-type, rad54-1 and rad54-2 mutants measured using I2fg fluorescent-tagged lines. Genetic distances (in centiMorgans, $\mathrm{cM}$ ) calculated from tetrad analysis of the I2f and I2g intervals on chromosome 2. Bars indicate mean \pm SD. For both 
intervals, WT and rad54 plants do not significantly differ $(\mathrm{p}<0.05$; Z-test).

(TIFF)

S5 Fig. Absence of synapsis in $\mathbf{d m c 1}$ rad54 mutant plants. Immunolocalization in wild-type, rad54-2 and $d m c 1$ rad54-2 meiocytes shows that synaptonemal complex transverse filament protein, ZYP1, is not correctly loaded along chromosome axes in $\mathrm{dmc1}$ rad54-2 indicating lack of synapsis. DAPI (blue), ASY1 (red), ZYP1 (green) and merged images are shown. (Scale Bar: $5 \mu \mathrm{m})$.

S6 Fig. Fertility of $d m c 1$ rad54-1 and $d m c 1$ rad54-2 mutant plants. Number of seeds per silique in Wild-type, $d m c 1, d m c 1$ rad54-1 and $d m c 1$ rad54-2 mutants. Each spot represents the number of seeds in one silique. Bars indicate mean \pm SD. ${ }^{* * * *}$ : significantly different.

$\mathrm{P}<0.0001$ (unpaired, two-tailed Mann-Whitney test).

(TIFF)

S7 Fig. Absence of RAD54 leads to partial chromosome fragmentation in sds meiosis. (A) Male meiosis is shown in wild-type, $s d s$ rad54-1, and $s d s$ rad54-2. Chromosomes were spread and stained with DAPI. (Scale bar $=10 \mu \mathrm{m}$ ). (B) Quantification of male meiocytes showing intact chromosomes or fragmentation. Each bar represents one plant.

S8 Fig. RAD51 foci in wild type and rad54 mutant pachytene cells. (A) Dual immunolocalization of ZYP1 (green) and RAD51 (red) in wild-type and rad54-2 pachytene cells. (Scale Bar: $5 \mu \mathrm{m}$ ). (B) Quantification of RAD51 foci per positive pachytene cell in wild-type and rad54-2 mutants. Means \pm SD are indicated. n.s.: not significantly different ( $\mathrm{p}$-value $>0.05$, unpaired, two-tailed Mann-Whitney test).

(TIFF)

S1 Table. FTLs raw data and Interference ratio calculation. Tetrad count for all tetrad categories for I1 bc and I2fg intervals. Tetrad categories (a to l) were classified as described previously by Berchowitz and Copenhaver (2008).

(XLSX)

S1 Data. Raw data for fertility and RAD51 foci countings. This are numerical data that supports the findings of this study.

(XLSX)

\section{Acknowledgments}

We thank Gregory Copenhaver and Ian Henderson for FTL lines, Chris Franklin and Peter Schlögelhofer for providing the ASY1 and RAD51 antibodies, respectively and Mathilde Grelon and Rajeev Kumar for sharing ZYP1 antibody and $s d s$ mutant seeds. We thank members of the recombination group for their help and discussions.

\section{Author Contributions}

Conceptualization: Maria E. Gallego, Charles I. White, Olivier Da Ines.

Formal analysis: Miguel Hernandez Sanchez-Rebato, Alida M. Bouatta, Charles I. White, Olivier Da Ines.

Funding acquisition: Maria E. Gallego, Charles I. White, Olivier Da Ines.

Investigation: Miguel Hernandez Sanchez-Rebato, Alida M. Bouatta, Olivier Da Ines. 
Supervision: Maria E. Gallego, Charles I. White, Olivier Da Ines.

Writing - original draft: Charles I. White, Olivier Da Ines.

Writing - review \& editing: Maria E. Gallego, Charles I. White, Olivier Da Ines.

\section{References}

1. Heyer WD, Ehmsen KT, Liu J. Regulation of homologous recombination in eukaryotes. Annu Rev Genet. 2010; 44:113-39. https://doi.org/10.1146/annurev-genet-051710-150955 PMID: 20690856.

2. Ranjha L, Howard SM, Cejka P. Main steps in DNA double-strand break repair: an introduction to homologous recombination and related processes. Chromosoma. 2018; 127(2):187-214. https://doi. org/10.1007/s00412-017-0658-1 PMID: 29327130.

3. Mercier R, Mezard C, Jenczewski E, Macaisne N, Grelon M. The molecular biology of meiosis in plants. Annu Rev Plant Biol. 2015; 66:297-327. https://doi.org/10.1146/annurev-arplant-050213035923 PMID: 25494464.

4. Hunter N. Meiotic Recombination: The Essence of Heredity. Cold Spring Harb Perspect Biol. 2015; 7 (12). https://doi.org/10.1101/cshperspect.a016618 PMID: 26511629.

5. Symington LS. Mechanism and regulation of DNA end resection in eukaryotes. Crit Rev Biochem Mol Biol. 2016; 51(3):195-212. https://doi.org/10.3109/10409238.2016.1172552 PMID: 27098756.

6. Chen H, Lisby M, Symington LS. RPA coordinates DNA end resection and prevents formation of DNA hairpins. Mol Cell. 2013; 50(4):589-600. https://doi.org/10.1016/j.molcel.2013.04.032 PMID: 23706822.

7. Chen R, Wold MS. Replication protein A: single-stranded DNA's first responder: dynamic DNAinteractions allow replication protein A to direct single-strand DNA intermediates into different pathways for synthesis or repair. Bioessays. 2014; 36(12):1156-61. https://doi.org/10.1002/bies. 201400107 PMID: 25171654.

8. Brown MS, Bishop DK. DNA strand exchange and RecA homologs in meiosis. Cold Spring Harb Perspect Biol. 2014; 7(1):a016659. https://doi.org/10.1101/cshperspect.a016659 PMID: 25475089.

9. Crickard JB, Greene EC. Biochemical attributes of mitotic and meiotic presynaptic complexes. DNA Repair (Amst). 2018; 71:148-57. https://doi.org/10.1016/j.dnarep.2018.08.018 PMID: 30195641.

10. Kowalczykowski SC. An Overview of the Molecular Mechanisms of Recombinational DNA Repair. Cold Spring Harb Perspect Biol. 2015; 7(11). https://doi.org/10.1101/cshperspect.a016410 PMID: 26525148.

11. Zelensky A, Kanaar R, Wyman C. Mediators of homologous DNA pairing. Cold Spring Harb Perspect Biol. 2014; 6(12):a016451. https://doi.org/10.1101/cshperspect.a016451 PMID: 25301930.

12. Suwaki N, Klare $K$, Tarsounas M. RAD51 paralogs: roles in DNA damage signalling, recombinational repair and tumorigenesis. Semin Cell Dev Biol. 2011; 22(8):898-905. https://doi.org/10.1016/j. semcdb.2011.07.019 PMID: 21821141.

13. Pradillo $\mathrm{M}$, Varas J, Oliver $\mathrm{C}$, Santos $\mathrm{JL}$. On the role of AtDMC1, AtRAD51 and its paralogs during Arabidopsis meiosis. Front Plant Sci. 2014; 5:23. https://doi.org/10.3389/fpls.2014.00023 PMID: 24596572.

14. Liu J, Renault L, Veaute X, Fabre F, Stahlberg H, Heyer WD. Rad51 paralogues Rad55-Rad57 balance the antirecombinase Srs2 in Rad51 filament formation. Nature. 2011; 479(7372):245-8. https:// doi.org/10.1038/nature10522 PMID: 22020281.

15. Gasior SL, Olivares H, Ear U, Hari DM, Weichselbaum R, Bishop DK. Assembly of RecA-like recombinases: distinct roles for mediator proteins in mitosis and meiosis. Proc Natl Acad Sci U S A. 2001; 98 (15):8411-8. https://doi.org/10.1073/pnas.121046198 PMID: 11459983.

16. Gasior SL, Wong AK, Kora Y, Shinohara A, Bishop DK. Rad52 associates with RPA and functions with rad55 and rad57 to assemble meiotic recombination complexes. Genes Dev. 1998; 12(14):2208-21. https://doi.org/10.1101/gad.12.14.2208 PMID: 9679065.

17. Schwacha A, Kleckner N. Interhomolog bias during meiotic recombination: meiotic functions promote a highly differentiated interhomolog-only pathway. Cell. 1997; 90(6):1123-35. https://doi.org/10.1016/ s0092-8674(00)80378-5 PMID: 9323140.

18. Sasanuma $H$, Tawaramoto MS, Lao JP, Hosaka H, Sanda E, Suzuki M, et al. A new protein complex promoting the assembly of Rad51 filaments. Nat Commun. 2013; 4:1676. https://doi.org/10.1038/ ncomms2678 PMID: 23575680.

19. Serra H, Da Ines O, Degroote F, Gallego ME, White Cl. Roles of XRCC2, RAD51B and RAD51D in RAD51-independent SSA recombination. PLoS Genet. 2013; 9(11):e1003971. https://doi.org/10. 1371/journal.pgen.1003971 PMID: 24278037. 
20. Kuznetsov S, Pellegrini M, Shuda K, Fernandez-Capetillo O, Liu Y, Martin BK, et al. RAD51C deficiency in mice results in early prophase I arrest in males and sister chromatid separation at metaphase II in females. J Cell Biol. 2007; 176(5):581-92. https://doi.org/10.1083/jcb.200608130 PMID: 17312021.

21. Liu Y, Tarsounas M, O'Regan $P$, West SC. Role of RAD51C and XRCC3 in genetic recombination and DNA repair. J Biol Chem. 2007; 282(3):1973-9. https://doi.org/10.1074/jbc.M609066200 PMID: 17114795.

22. Zhang B, Wang M, Tang D, Li Y, Xu M, Gu M, et al. XRCC3 is essential for proper double-strand break repair and homologous recombination in rice meiosis. J Exp Bot. 2015; 66(19):5713-25. https://doi. org/10.1093/jxb/erv253 PMID: 26034131.

23. Tang D, Miao C, Li Y, Wang H, Liu X, Yu H, et al. OsRAD51C is essential for double-strand break repair in rice meiosis. Front Plant Sci. 2014; 5:167. https://doi.org/10.3389/fpls.2014.00167 PMID: 24847337.

24. Su H, Cheng Z, Huang J, Lin J, Copenhaver GP, Ma H, et al. Arabidopsis RAD51, RAD51C and XRCC3 proteins form a complex and facilitate RAD51 localization on chromosomes for meiotic recombination. PLoS Genet. 2017; 13(5):e1006827. https://doi.org/10.1371/journal.pgen.1006827 PMID: 28562599.

25. Abe K, Osakabe K, Nakayama S, Endo M, Tagiri A, Todoriki S, et al. Arabidopsis RAD51C gene is important for homologous recombination in meiosis and mitosis. Plant Physiol. 2005; 139(2):896-908. https://doi.org/10.1104/pp.105.065243 PMID: 16169964.

26. Bleuyard JY, Gallego ME, Savigny F, White Cl. Differing requirements for the Arabidopsis Rad51 paralogs in meiosis and DNA repair. Plant J. 2005; 41(4):533-45. https://doi.org/10.1111/j.1365-313X. 2004.02318.x PMID: 15686518.

27. Bleuyard JY, Gallego ME, White $\mathrm{Cl}$. The atspo11-1 mutation rescues atxrcc3 meiotic chromosome fragmentation. Plant Mol Biol. 2004; 56(2):217-24. https://doi.org/10.1007/s11103-004-2812-4 PMID: 15604739.

28. Bleuyard JY, White $\mathrm{Cl}$. The Arabidopsis homologue of Xrcc3 plays an essential role in meiosis. EMBO J. 2004; 23(2):439-49. https://doi.org/10.1038/sj.emboj.7600055 PMID: 14726957.

29. Li W, Yang X, Lin Z, Timofejeva L, Xiao R, Makaroff CA, et al. The AtRAD51C gene is required for normal meiotic chromosome synapsis and double-stranded break repair in Arabidopsis. Plant Physiol. 2005; 138(2):965-76. https://doi.org/10.1104/pp.104.058347 PMID: 15923332.

30. Cartwright R, Dunn AM, Simpson PJ, Tambini CE, Thacker J. Isolation of novel human and mouse genes of the recA/RAD51 recombination-repair gene family. Nucleic Acids Res. 1998; 26(7):1653-9. https://doi.org/10.1093/nar/26.7.1653 PMID: 9512535.

31. Cartwright $R$, Tambini CE, Simpson PJ, Thacker $J$. The XRCC2 DNA repair gene from human and mouse encodes a novel member of the recA/RAD51 family. Nucleic Acids Res. 1998; 26(13):3084-9. https://doi.org/10.1093/nar/26.13.3084 PMID: 9628903.

32. Tarsounas M, Munoz P, Claas A, Smiraldo PG, Pittman DL, Blasco MA, et al. Telomere maintenance requires the RAD51D recombination/repair protein. Cell. 2004; 117(3):337-47. https://doi.org/10. 1016/s0092-8674(04)00337-x PMID: 15109494.

33. Chen C, Farmer AD, Langley RJ, Mudge J, Crow JA, May GD, et al. Meiosis-specific gene discovery in plants: RNA-Seq applied to isolated Arabidopsis male meiocytes. BMC Plant Biol. 2010; 10:280. https://doi.org/10.1186/1471-2229-10-280 PMID: 21167045.

34. Walker J, Gao H, Zhang J, Aldridge B, Vickers M, Higgins JD, et al. Sexual-lineage-specific DNA methylation regulates meiosis in Arabidopsis. Nat Genet. 2018; 50(1):130-7. https://doi.org/10.1038/ s41588-017-0008-5 PMID: 29255257.

35. Yang $\mathrm{H}$, Lu P, Wang $\mathrm{Y}, \mathrm{Ma} \mathrm{H}$. The transcriptome landscape of Arabidopsis male meiocytes from highthroughput sequencing: the complexity and evolution of the meiotic process. Plant J. 2011;65(4):50316. https://doi.org/10.1111/j.1365-313X.2010.04439.x PMID: 21208307.

36. Yang Y, Guo J, Dai L, Zhu Y, Hu H, Tan L, et al. XRCC2 mutation causes meiotic arrest, azoospermia and infertility. J Med Genet. 2018; 55(9):628-36. https://doi.org/10.1136/jmedgenet-2017-105145 PMID: 30042186.

37. Byun MY, Kim WT. Suppression of OsRAD51D results in defects in reproductive development in rice (Oryza sativa L.). Plant J. 2014; 79(2):256-69. https://doi.org/10.1111/tpj.12558 PMID: 24840804.

38. Charlot F, Chelysheva L, Kamisugi Y, Vrielynck N, Guyon A, Epert A, et al. RAD51B plays an essential role during somatic and meiotic recombination in Physcomitrella. Nucleic Acids Res. 2014; 42 (19):11965-78. https://doi.org/10.1093/nar/gku890 PMID: 25260587.

39. Zhang F, Shen Y, Miao C, Cao Y, Shi W, Du G, et al. OsRAD51D promotes homologous pairing and recombination by preventing non-homologous interactions in rice meiosis. New Phytol. 2020. https:// doi.org/10.1111/nph.16595 PMID: 32275774. 
40. Osakabe K, Abe K, Yamanouchi H, Takyuu T, Yoshioka T, Ito Y, et al. Arabidopsis Rad51B is important for double-strand DNA breaks repair in somatic cells. Plant Mol Biol. 2005; 57(6):819-33. https:// doi.org/10.1007/s11103-005-2187-1 PMID: 15952068.

41. Da Ines O, Degroote F, Amiard S, Goubely C, Gallego ME, White Cl. Effects of XRCC2 and RAD51B mutations on somatic and meiotic recombination in Arabidopsis thaliana. Plant J. 2013; 74(6):959-70. https://doi.org/10.1111/tpj.12182 PMID: 23521529.

42. Wang Y, Xiao R, Wang H, Cheng Z, Li W, Zhu G, et al. The Arabidopsis RAD51 paralogs RAD51B, RAD51D and XRCC2 play partially redundant roles in somatic DNA repair and gene regulation. New Phytol. 2014; 201(1):292-304. https://doi.org/10.1111/nph.12498 PMID: 24102485.

43. Abreu CM, Prakash R, Romanienko PJ, Roig I, Keeney S, Jasin M. Shu complex SWS1-SWSAP1 promotes early steps in mouse meiotic recombination. Nat Commun. 2018; 9(1):3961. https://doi.org/10. 1038/s41467-018-06384-x PMID: 30305635.

44. Ceballos SJ, Heyer WD. Functions of the Snf2/Swi2 family Rad54 motor protein in homologous recombination. Biochim Biophys Acta. 2011; 1809(9):509-23. https://doi.org/10.1016/j.bbagrm.2011.06.006 PMID: 21704205.

45. Crickard JB, Greene EC. Helicase Mechanisms During Homologous Recombination in Saccharomyces cerevisiae. Annu Rev Biophys. 2019. https://doi.org/10.1146/annurev-biophys-052118-115418 PMID: 30857400.

46. Mazin AV, Mazina OM, Bugreev DV, Rossi MJ. Rad54, the motor of homologous recombination. DNA Repair (Amst). 2010; 9(3):286-302. https://doi.org/10.1016/j.dnarep.2009.12.006 PMID: 20089461.

47. Ghabrial A, Ray RP, Schupbach T. okra and spindle-B encode components of the RAD52 DNA repair pathway and affect meiosis and patterning in Drosophila oogenesis. Genes Dev. 1998; 12(17):271123. https://doi.org/10.1101/gad.12.17.2711 PMID: 9732269.

48. Kooistra R, Vreeken K, Zonneveld JB, de Jong A, Eeken JC, Osgood CJ, et al. The Drosophila melanogaster RAD54 homolog, DmRAD54, is involved in the repair of radiation damage and recombination. Mol Cell Biol. 1997; 17(10):6097-104. https://doi.org/10.1128/mcb.17.10.6097 PMID: 9315669.

49. Mets DG, Meyer BJ. Condensins regulate meiotic DNA break distribution, thus crossover frequency, by controlling chromosome structure. Cell. 2009; 139(1):73-86. https://doi.org/10.1016/j.cell.2009.07. 035 PMID: 19781752.

50. Bishop DK, Park D, Xu L, Kleckner N. DMC1: a meiosis-specific yeast homolog of E. coli recA required for recombination, synaptonemal complex formation, and cell cycle progression. Cell. 1992; 69 (3):439-56. https://doi.org/10.1016/0092-8674(92)90446-j PMID: 1581960.

51. Cloud V, Chan YL, Grubb J, Budke B, Bishop DK. Rad51 is an accessory factor for Dmc1-mediated joint molecule formation during meiosis. Science. 2012; 337(6099):1222-5. https://doi.org/10.1126/ science.1219379 PMID: 22955832.

52. Da Ines O, Degroote F, Goubely C, Amiard S, Gallego ME, White Cl. Meiotic recombination in Arabidopsis is catalysed by DMC1, with RAD51 playing a supporting role. PLoS Genet. 2013; 9(9): e1003787. https://doi.org/10.1371/journal.pgen.1003787 PMID: 24086145.

53. Niu H, Wan L, Busygina V, Kwon Y, Allen JA, Li X, et al. Regulation of meiotic recombination via Mek1mediated Rad54 phosphorylation. Mol Cell. 2009; 36(3):393-404. https://doi.org/10.1016/j.molcel. 2009.09.029 PMID: 19917248.

54. Tsubouchi $\mathrm{H}$, Roeder GS. Budding yeast Hed1 down-regulates the mitotic recombination machinery when meiotic recombination is impaired. Genes Dev. 2006; 20(13):1766-75. https://doi.org/10.1101/ gad.1422506 PMID: 16818607.

55. Callender TL, Laureau R, Wan L, Chen X, Sandhu R, Laljee S, et al. Mek1 Down Regulates Rad51 Activity during Yeast Meiosis by Phosphorylation of Hed1. PLoS Genet. 2016; 12(8):e1006226. https://doi.org/10.1371/journal.pgen.1006226 PMID: 27483004.

56. Lao JP, Cloud V, Huang CC, Grubb J, Thacker D, Lee CY, et al. Meiotic crossover control by concerted action of Rad51-Dmc1 in homolog template bias and robust homeostatic regulation. PLoS Genet. 2013; 9(12):e1003978. https://doi.org/10.1371/journal.pgen.1003978 PMID: 24367271.

57. Busygina V, Saro D, Williams G, Leung WK, Say AF, Sehorn MG, et al. Novel attributes of Hed1 affect dynamics and activity of the Rad51 presynaptic filament during meiotic recombination. J Biol Chem. 2012; 287(2):1566-75. https://doi.org/10.1074/jbc.M111.297309 PMID: 22115747.

58. Busygina V, Sehorn MG, Shi IY, Tsubouchi H, Roeder GS, Sung P. Hed1 regulates Rad51-mediated recombination via a novel mechanism. Genes Dev. 2008; 22(6):786-95. https://doi.org/10.1101/gad. 1638708 PMID: 18347097.

59. Hong S, Sung Y, Yu M, Lee M, Kleckner N, Kim KP. The logic and mechanism of homologous recombination partner choice. Mol Cell. 2013; 51(4):440-53. https://doi.org/10.1016/j.molcel.2013.08.008 PMID: 23973374. 
60. Crickard JB, Kaniecki K, Kwon Y, Sung P, Lisby M, Greene EC. Regulation of Hed1 and Rad54 binding during maturation of the meiosis-specific presynaptic complex. EMBO J. 2018; 37(7). https://doi.org/ 10.15252/embj.201798728 PMID: 29444896.

61. Liu Y, Gaines WA, Callender T, Busygina V, Oke A, Sung P, et al. Down-regulation of Rad51 activity during meiosis in yeast prevents competition with Dmc1 for repair of double-strand breaks. PLoS Genet. 2014; 10(1):e1004005. https://doi.org/10.1371/journal.pgen.1004005 PMID: 24465215.

62. Arbel A, Zenvirth D, Simchen G. Sister chromatid-based DNA repair is mediated by RAD54, not by DMC1 or TID1. EMBO J. 1999; 18(9):2648-58. https://doi.org/10.1093/emboj/18.9.2648 PMID: 10228176.

63. Bishop DK, Nikolski Y, Oshiro J, Chon J, Shinohara M, Chen X. High copy number suppression of the meiotic arrest caused by a dmc1 mutation: REC114 imposes an early recombination block and RAD54 promotes a DMC1-independent DSB repair pathway. Genes Cells. 1999; 4(8):425-44. https://doi.org/ 10.1046/j.1365-2443.1999.00273.x PMID: 10526232.

64. Catlett MG, Forsburg SL. Schizosaccharomyces pombe Rdh54 (TID1) acts with Rhp54 (RAD54) to repair meiotic double-strand breaks. Mol Biol Cell. 2003; 14(11):4707-20. https://doi.org/10.1091/ mbc.e03-05-0288 PMID: 14551247.

65. Schmuckli-Maurer J, Heyer WD. Meiotic recombination in RAD54 mutants of Saccharomyces cerevisiae. Chromosoma. 2000; 109(1-2):86-93. https://doi.org/10.1007/s004120050415 PMID: 10855498.

66. Shinohara M, Gasior SL, Bishop DK, Shinohara A. Tid1/Rdh54 promotes colocalization of rad51 and dmc1 during meiotic recombination. Proc Natl Acad Sci U S A. 2000; 97(20):10814-9. https://doi.org/ 10.1073/pnas.97.20.10814 PMID: 11005857.

67. Shinohara M, Sakai K, Shinohara A, Bishop DK. Crossover interference in Saccharomyces cerevisiae requires a TID1/RDH54- and DMC1-dependent pathway. Genetics. 2003; 163(4):1273-86. PMID: 12702674.

68. Shinohara M, Shita-Yamaguchi E, Buerstedde JM, Shinagawa H, Ogawa H, Shinohara A. Characterization of the roles of the Saccharomyces cerevisiae RAD54 gene and a homologue of RAD54, RDH54/TID1, in mitosis and meiosis. Genetics. 1997; 147(4):1545-56. PMID: 9409820.

69. Subramanian VV, MacQueen AJ, Vader G, Shinohara M, Sanchez A, Borde V, et al. Chromosome Synapsis Alleviates Mek1-Dependent Suppression of Meiotic DNA Repair. PLoS Biol. 2016; 14(2): e1002369. https://doi.org/10.1371/journal.pbio.1002369 PMID: 26870961.

70. Nimonkar AV, Dombrowski CC, Siino JS, Stasiak AZ, Stasiak A, Kowalczykowski SC. Saccharomyces cerevisiae Dmc1 and Rad51 proteins preferentially function with Tid1 and Rad54 proteins, respectively, to promote DNA strand invasion during genetic recombination. J Biol Chem. 2012; 287 (34):28727-37. https://doi.org/10.1074/jbc.M112.373290 PMID: 22761450.

71. Essers J, Hendriks RW, Swagemakers SM, Troelstra C, de Wit J, Bootsma D, et al. Disruption of mouse RAD54 reduces ionizing radiation resistance and homologous recombination. Cell. 1997; 89 (2):195-204. https://doi.org/10.1016/s0092-8674(00)80199-3 PMID: 9108475.

72. Wesoly J, Agarwal S, Sigurdsson S, Bussen W, Van Komen S, Qin J, et al. Differential contributions of mammalian Rad54 paralogs to recombination, DNA damage repair, and meiosis. Mol Cell Biol. 2006; 26(3):976-89. https://doi.org/10.1128/MCB.26.3.976-989.2006 PMID: 16428451.

73. Klutstein M, Shaked H, Sherman A, Avivi-Ragolsky N, Shema E, Zenvirth D, et al. Functional conservation of the yeast and Arabidopsis RAD54-like genes. Genetics. 2008; 178(4):2389-97. https://doi. org/10.1534/genetics.108.086777 PMID: 18430956.

74. Hirakawa T, Hasegawa J, White $\mathrm{Cl}$, Matsunaga S. RAD54 forms DNA repair foci in response to DNA damage in living plant cells. Plant J. 2017; 90(2):372-82. https://doi.org/10.1111/tpj.13499 PMID: 28155243.

75. Hirakawa T, Katagiri Y, Ando T, Matsunaga S. DNA double-strand breaks alter the spatial arrangement of homologous loci in plant cells. Sci Rep. 2015; 5:11058. https://doi.org/10.1038/srep11058 PMID: 26046331.

76. Osakabe K, Abe K, Yoshioka T, Osakabe Y, Todoriki S, Ichikawa H, et al. Isolation and characterization of the RAD54 gene from Arabidopsis thaliana. Plant J. 2006; 48(6):827-42. https://doi.org/10. 1111/j.1365-313X.2006.02927.x PMID: 17227544.

77. Roth N, Klimesch J, Dukowic-Schulze S, Pacher M, Mannuss A, Puchta H. The requirement for recombination factors differs considerably between different pathways of homologous double-strand break repair in somatic plant cells. Plant J. 2012; 72(5):781-90. https://doi.org/10.1111/j.1365-313X.2012. 05119.x PMID: 22860689.

78. Shaked H, Avivi-Ragolsky N, Levy AA. Involvement of the Arabidopsis SWI2/SNF2 chromatin remodeling gene family in DNA damage response and recombination. Genetics. 2006; 173(2):985-94. https://doi.org/10.1534/genetics.105.051664 PMID: 16547115. 
79. Mannuss A, Dukowic-Schulze S, Suer S, Hartung F, Pacher M, Puchta H. RAD5A, RECQ4A, and MUS81 have specific functions in homologous recombination and define different pathways of DNA repair in Arabidopsis thaliana. Plant Cell. 2010; 22(10):3318-30. https://doi.org/10.1105/tpc.110. 078568 PMID: 20971895.

80. Crismani W, Mercier R. Identifying meiotic mutants in Arabidopsis thaliana. Methods Mol Biol. 2013; 990:227-34. https://doi.org/10.1007/978-1-62703-333-6_22 PMID: 23559218.

81. Berchowitz LE, Copenhaver GP. Fluorescent Arabidopsis tetrads: a visual assay for quickly developing large crossover and crossover interference data sets. Nat Protoc. 2008; 3(1):41-50. https://doi. org/10.1038/nprot.2007.491 PMID: 18193020.

82. Francis KE, Lam SY, Harrison BD, Bey AL, Berchowitz LE, Copenhaver GP. Pollen tetrad-based visual assay for meiotic recombination in Arabidopsis. Proc Natl Acad Sci U S A. 2007; 104(10):3913-8. https://doi.org/10.1073/pnas.0608936104 PMID: 17360452.

83. Francis KE, Lam SY, Copenhaver GP. Separation of Arabidopsis pollen tetrads is regulated by QUARTET1, a pectin methylesterase gene. Plant Physiol. 2006; 142(3):1004-13. https://doi.org/10.1104/pp. 106.085274 PMID: 16980565.

84. Couteau F, Belzile F, Horlow C, Grandjean O, Vezon D, Doutriaux MP. Random chromosome segregation without meiotic arrest in both male and female meiocytes of a dmc1 mutant of Arabidopsis. Plant Cell. 1999; 11(9):1623-34. https://doi.org/10.1105/tpc.11.9.1623 PMID: 10488231.

85. Pradillo M, Lopez E, Linacero R, Romero C, Cunado N, Sanchez-Moran E, et al. Together yes, but not coupled: new insights into the roles of RAD51 and DMC1 in plant meiotic recombination. Plant J. 2012; 69(6):921-33. https://doi.org/10.1111/j.1365-313X.2011.04845.x PMID: 22066484.

86. Crismani W, Portemer V, Froger N, Chelysheva L, Horlow C, Vrielynck N, et al. MCM8 is required for a pathway of meiotic double-strand break repair independent of DMC1 in Arabidopsis thaliana. PLoS Genet. 2013; 9(1):e1003165. https://doi.org/10.1371/journal.pgen.1003165 PMID: 23300481.

87. Azumi Y, Liu D, Zhao D, Li W, Wang G, Hu Y, et al. Homolog interaction during meiotic prophase I in Arabidopsis requires the SOLO DANCERS gene encoding a novel cyclin-like protein. EMBO J. 2002; 21(12):3081-95. https://doi.org/10.1093/emboj/cdf285 PMID: 12065421.

88. De Muyt A, Pereira L, Vezon D, Chelysheva L, Gendrot G, Chambon A, et al. A high throughput genetic screen identifies new early meiotic recombination functions in Arabidopsis thaliana. PLoS Genet. 2009; 5(9):e1000654. https://doi.org/10.1371/journal.pgen.1000654 PMID: 19763177.

89. Fernandes JB, Duhamel M, Seguela-Arnaud M, Froger N, Girard C, Choinard S, et al. FIGL1 and its novel partner FLIP form a conserved complex that regulates homologous recombination. PLoS Genet. 2018; 14(4):e1007317. https://doi.org/10.1371/journal.pgen.1007317 PMID: 29608566.

90. Girard C, Chelysheva L, Choinard S, Froger N, Macaisne N, Lemhemdi A, et al. AAA-ATPase FIDGETIN-LIKE 1 and Helicase FANCM Antagonize Meiotic Crossovers by Distinct Mechanisms. PLoS Genet. 2015; 11(7):e1005369. https://doi.org/10.1371/journal.pgen.1005369 PMID: 26161528.

91. Agarwal S, van Cappellen WA, Guenole A, Eppink B, Linsen SE, Meijering E, et al. ATP-dependent and independent functions of Rad54 in genome maintenance. J Cell Biol. 2011; 192(5):735-50. https://doi.org/10.1083/jcb.201011025 PMID: 21357745.

92. Solinger JA, Kiianitsa K, Heyer WD. Rad54, a Swi2/Snf2-like recombinational repair protein, disassembles Rad51:dsDNA filaments. Mol Cell. 2002; 10(5):1175-88. https://doi.org/10.1016/s1097-2765 (02)00743-8 PMID: 12453424.

93. Zhang Z, Fan HY, Goldman JA, Kingston RE. Homology-driven chromatin remodeling by human RAD54. Nat Struct Mol Biol. 2007; 14(5):397-405. https://doi.org/10.1038/nsmb1223 PMID: 17417655.

94. Argunhan B, Leung WK, Afshar N, Terentyev $Y$, Subramanian VV, Murayama $Y$, et al. Fundamental cell cycle kinases collaborate to ensure timely destruction of the synaptonemal complex during meiosis. EMBO J. 2017; 36(17):2488-509. https://doi.org/10.15252/embj.201695895 PMID: 28694245.

95. Prugar E, Burnett C, Chen X, Hollingsworth NM. Coordination of Double Strand Break Repair and Meiotic Progression in Yeast by a Mek1-Ndt80 Negative Feedback Loop. Genetics. 2017; 206(1):497512. https://doi.org/10.1534/genetics.117.199703 PMID: 28249986.

96. Uanschou C, Ronceret A, Von Harder M, De Muyt A, Vezon D, Pereira L, et al. Sufficient amounts of functional HOP2/MND1 complex promote interhomolog DNA repair but are dispensable for intersister DNA repair during meiosis in Arabidopsis. Plant Cell. 2013; 25(12):4924-40. https://doi.org/10.1105/ tpc.113.118521 PMID: 24363313.

97. Daley JM, Gaines WA, Kwon Y, Sung P. Regulation of DNA pairing in homologous recombination. Cold Spring Harb Perspect Biol. 2014; 6(11):a017954. https://doi.org/10.1101/cshperspect.a017954 PMID: 25190078.

98. Knizewski L, Ginalski K, Jerzmanowski A. Snf2 proteins in plants: gene silencing and beyond. Trends Plant Sci. 2008; 13(10):557-65. https://doi.org/10.1016/j.tplants.2008.08.004 PMID: 18786849. 
99. Singh G, Da Ines O, Gallego ME, White Cl. Analysis of the impact of the absence of RAD51 strand exchange activity in Arabidopsis meiosis. PLoS One. 2017; 12(8):e0183006. https://doi.org/10.1371/ journal.pone.0183006 PMID: 28797117.

100. Vignard J, Siwiec T, Chelysheva L, Vrielynck N, Gonord F, Armstrong SJ, et al. The interplay of RecArelated proteins and the MND1-HOP2 complex during meiosis in Arabidopsis thaliana. PLoS Genet. 2007; 3(10):1894-906. https://doi.org/10.1371/journal.pgen.0030176 PMID: 17937504.

101. Sandhu R, Monge Neria F, Monge Neria J, Chen X, Hollingsworth NM, Borner GV. DNA Helicase Mph1(FANCM) Ensures Meiotic Recombination between Parental Chromosomes by Dissociating Precocious Displacement Loops. Dev Cell. 2020; 53(4):458-72 e5. https://doi.org/10.1016/j.devcel.2020. 04.010 PMID: 32386601.

102. Alonso JM, Stepanova AN, Leisse TJ, Kim CJ, Chen H, Shinn P, et al. Genome-wide insertional mutagenesis of Arabidopsis thaliana. Science. 2003; 301(5633):653-7. https://doi.org/10.1126/science. 1086391 PMID: 12893945.

103. Li W, Chen C, Markmann-Mulisch U, Timofejeva L, Schmelzer E, Ma H, et al. The Arabidopsis AtRAD51 gene is dispensable for vegetative development but required for meiosis. Proc Natl Acad Sci U S A. 2004; 101(29):10596-601. https://doi.org/10.1073/pnas.0404110101 PMID: 15249667.

104. Ross KJ, Fransz P, Jones GH. A light microscopic atlas of meiosis in Arabidopsis thaliana. Chromosome Res. 1996; 4(7):507-16. https://doi.org/10.1007/BF02261778 PMID: 8939362.

105. Armstrong SJ, Caryl AP, Jones GH, Franklin FC. Asy1, a protein required for meiotic chromosome synapsis, localizes to axis-associated chromatin in Arabidopsis and Brassica. J Cell Sci. 2002; 115(Pt 18):3645-55. https://doi.org/10.1242/jcs.00048 PMID: 12186950.

106. Higgins JD, Armstrong SJ, Franklin FC, Jones GH. The Arabidopsis MutS homolog AtMSH4 functions at an early step in recombination: evidence for two classes of recombination in Arabidopsis. Genes Dev. 2004; 18(20):2557-70. https://doi.org/10.1101/gad.317504 PMID: 15489296.

107. Kurzbauer MT, Uanschou $C$, Chen D, Schlogelhofer $P$. The recombinases DMC1 and RAD51 are functionally and spatially separated during meiosis in Arabidopsis. Plant Cell. 2012; 24(5):2058-70. https://doi.org/10.1105/tpc.112.098459 PMID: 22589466.

108. Higgins JD, Sanchez-Moran E, Armstrong SJ, Jones GH, Franklin FC. The Arabidopsis synaptonemal complex protein ZYP1 is required for chromosome synapsis and normal fidelity of crossing over. Genes Dev. 2005; 19(20):2488-500. https://doi.org/10.1101/gad.354705 PMID: 16230536. 